Article

\title{
Techno-Economic Feasibility Study of Small Wind Turbines in the Valley of Mexico Metropolitan Area
}

\author{
Osvaldo Rodriguez-Hernandez ${ }^{1, *,+} \oplus$, Manuel Martinez ${ }^{1,+}{ }^{\oplus}$, , Carlos Lopez-Villalobos ${ }^{2,+} \oplus$, \\ Hector Garcia ${ }^{3}$ and Rafael Campos-Amezcua ${ }^{4}$ \\ 1 Instituto de Energías Renovables. Universidad Nacional Autónoma de México, A.P. 34, 62580 Temixco, \\ Mor. México, Mexico; mmf@ier.unam.mx \\ 2 Posgrado en Ingeniería (Energía), Universidad Nacional Autónoma de México, A.P. 34, 62580 Temixco, \\ Mor. México, Mexico; calovi@ier.unam.mx \\ 3 Independent Researcher, Morelia 58120, Mich., Mexico; hegaviv@gmail.com \\ 4 Tecnológico Nacional de México/Instituto Tecnológico de Pachuca, Carr. México-Pachuca km 87.5, Col. \\ Venta Prieta, C.P. 42080, Pachuca, Hgo., Mexico; rcampos_amezcua@yahoo.com.mx \\ * Correspondence: osroh@ier.unam.mx; Tel.: +52-(777)-362-0090 (ext. 38009) \\ + These authors contributed equally to this work.
}

Received: 8 January 2019; Accepted: 16 February 2019; Published: 7 March 2019

check for updates

\begin{abstract}
The use of small wind turbines (SWTs) is an alternative energy strategy with increasing potential for satisfying in situ electrical demands and should be studied to promote social penetration. The Valley of Mexico Metropolitan Area (VMMA) has air pollution issues that need to be addressed. This has resulted in programs for monitoring atmospheric variables, such as wind speed. By selecting and using 3 years' worth of available data, we developed a methodology to study the technical and economic feasibility of using SWTs in the VMMA. To this end, 28 SWT models were assessed at 18 locations to estimate annual energy production. In light of certain data characteristics, an adjustment to the power production was proposed for the specific case of using SWTs. Cash flow analysis and annualized net present value (ANPV) were used to determine economic feasibility for each location; furthermore, electric home feeds in the VMMA were considered to model local economic conditions. Similar wind conditions were observed within the VMMA; however, only two wind turbine and location models provided positive ANPV values. The extra annual benefit for each project was calculated by associating the cost per mitigation of $\mathrm{CO}_{2}$ emissions, which may provide an economic strategy for promoting the penetration of this technology.
\end{abstract}

Keywords: resource assessment; wind power; distributed generation; Rayleigh distribution; urban environment

\section{Introduction}

As an electricity supply source, wind power is one of the most popular options for avoiding greenhouse gas emission products from fossil fuel combustion, which has a major impact on global warming. This renewable energy source is currently a competitive solution in the electric market. Proof of its efficiency includes the global cumulative installed capacity of 539,123 MW [1] at the end of 2016 and the competitive costs around the world [2]. For example, the average levelized cost of energy in the USA in 2015 was 44 USD/MWh [3].

Electric production using wind turbines has versatile applications, the most popular being the wind farm. However, this is not the only means by which wind can be used to supply electricity. The application of small wind turbines (SWTs) for the decentralized use of energy [4] is a popular option for isolated grids, rural residential electrification, and hybrid systems [5]. 
Furthermore, wind energy in urban environments is an open opportunity in several areas: renewable electrical generation, ventilation, pollution dispersion, and mitigation of the urban heat-island effect. Although technical issues must be solved to reach technological maturity, the literature includes examples in which the electricity generated could satisfy around $5-40 \%$ of the local demand using vertical-axis wind turbines (VAWTs) [6].

In recent years, SWT applications have become a popular option for satisfying in situ demand. In 2014, the worldwide installed capacity was $830,332 \mathrm{~kW}$, distributed among China, the USA, and the UK, which together represent $86 \%$ of the sector [5]. On average, the power of each installed SWT in 2014 was $0.87 \mathrm{~kW}$, and the main applications are oriented toward satisfying off-grid demands. Initial costs in the US range from $6840 \mathrm{USD} / \mathrm{kW}$, corresponding to a wind turbine with a nominal power of less than $2.5 \mathrm{~kW}$, to $4710 \mathrm{USD} / \mathrm{kW}$, with a power range of 11-100 kW [7].

Around the world, small wind energy is moving toward becoming a competitive alternative to power distributed generation. Two factors influence its development: policies to promote the technology and the costs of the systems [8]. In this contribution, we study the resource assessment stage for SWT applications in an urban environment. The importance of resource assessment cannot be understated; its results and reliability (1) determine the development of the project, (2) are the basis of the techno-economical analysis, and (3) enable the development of economic scenarios that promote social penetration of these technologies.

Resource assessment is one of the most critical stages of any renewable energy project. Electricity production using wind power is calculated from wind speeds. Therefore, data quality is a crucial factor in power estimation. A complete review of the methodologies for resource assessment is presented in [9], and the research on urban wind energy is reviewed in [10]. For large wind turbines, the 10-min mean time has been considered to be a reliable method for power estimation and is widely reported in the literature. However, for small wind turbine applications, a reliable resource assessment is still a work in progress.

The literature includes studies aiming to determine the feasibility of implementing SWTs in urban environments throughout the world. In Greater London, the United Kingdom, the ideal regions for SWT electric generation were studied [11], and in Guelph, Ontario, Canada [12], it was estimated that SWTs could potentially supply $10 \%$ of the electric demand. In southern Italy [13], the techno-economic potential of this technology was analyzed, and in the Edinburgh Region [14], the wind speed potential from a meteorological database was found to be represented by a Weibull statistical model. The results of this study indicated that $72 \%$ of the time, wind speed was greater than $3 \mathrm{~m} / \mathrm{s}$, which is suitable for micro wind turbines. In the Gaza Region, a study analyzed the power produced by a $5 \mathrm{~kW}$ wind turbine, which was installable on the roof of a residential building, and the results indicated an annual capacity factor of $6 \%$; further, wind power production may be complemented by solar panels to improve power performance and to provide grid stability [15]. In this contribution, we present a technical analysis to describe the regional wind speed, and we assess different SWT models. This work is complemented by economic aspects that considering the Mexican electric context.

The power performance of an SWT is susceptible to wind resource availability. For example, local wind speed variability and high wind speeds that are available due to the building's altitude result in wind power integration being an attractive alternative to decentralized power generation [16,17]. Therefore, an accurate description of the wind conditions in these complex locations is crucial [18].

Urban environments are zones characterized by higher turbulence conditions that contain higher amounts of energy [19]. Recent work has shown evidence of an increase in SWT power production due to the energy contained in gusts [20]. This energy has effects on the output of a resource assessment analysis; there is a demonstrated relationship between the mean time of the wind speed used and the energy estimated [21]. Therefore, a proper characterization of wind conditions at the location of interest will improve the reliability of assessments for this technology.

An additional factor that can improve the reliability of the power resource assessment for SWT projects is the inclusion of a dynamic description of the device in the analysis. Reliable calculations 
require the selection of a proper mean time for the wind speed time series used to feed the model. In this way, it is possible to include the energy contained in the gusts in the assessment, and it may improve power estimations [22].

Although the reliability of the resource assessment can be improved by using wind speed data measured with specific characteristics and including specialized dynamic models, the development of the analysis becomes unfeasible for a domestic user. In this work, an adjustment to the methodology for estimating small wind turbine production is proposed: the proposed approach includes using data available from meteorological stations and calculating the differences in energy assessed according to time series averaged at different times.

The result of a resource assessment analysis is the calculated annual energy production of the selected SWT. The standard methodology for determining economic viability is to estimate the costs related to installation, operation, and maintenance. The latter factors are commonly associated with the lifetime of the technology. A cash flow model represents all components. Then, the relation between the energy produced and the costs of the project can be obtained. The levelized cost of energy can be calculated and complemented by other economic criteria, such as the time of investment return, cost-benefit analysis, etc. There are several examples of the use of this methodology that can be consulted [23-27].

Nevertheless, these parameters may not provide precise information to a potential domestic user of the technology in Mexico due to electric regulations. Thus, this methodology is adapted to describe the Mexican electrical tariff context where can be implemented these technologies for distributed generation. The model includes the perspective of the domestic user and allows to compare wind turbines with different lifetime. The objective is to provide a methodology that contributes to analyzing and delimiting economic strategies to promote the use of this renewable source of energy in this specific sector.

\section{Wind Power Sector in Mexico}

Geographically, the wind power potential in Mexico can be divided into five regions: the Isthmus of Tehuantepec, the State of Baja California, the Gulf of Mexico coast, the Coast of Yucatan, and the Northern-Central region [28]. Wind power resource assessment in Mexico has been studied in several works in the literature using different methodologies.

The Isthmus of Tehuantepec presents the most significant wind power potential in the country. This was the first zone studied for wind power generation [29]; nowadays, nearly $60 \%$ of the total installed capacity in the country is concentrated in this region [30]. A meteorological mesoscale model was used in the analysis, with a squared resolution of $2 \mathrm{~km}$ validated with 20 meteorological stations.

In Baja California, wind speed has great potential to participate in the transmission, distribution, and supply of electric energy to small urban zones [31]. The southern region of this state is characterized by geographic complexity and presents a technical challenge to electric grid integration; therefore, wind power has become a viable option for electric supply [32].

Veracruz and Tamaulipas are two states located on the coast of the Gulf of Mexico. In Veracruz, a wind persistence analysis was presented to study wind conditions for power production. Five meteorological stations were used with a mean time of $1 \mathrm{~h}$. The results indicated that wind conditions were suitable for wind power production [33]. A second study for the same state utilized seven meteorological stations and one anemometric tower to implement a statistical analysis of wind power potential in the region; the results agreed with those of the previous work [34].

In the coastal zone of Tamaulipas, a resource assessment analysis was developed; the methodology consisted of comparing four anemometric stations with the BMW-CERSAT reanalysis. Then, wind power potential was modeled using the Wind Atlas Analysis and Application Program (WAsP). Although the power density results differed from those of previous work, the Tamaulipas coast remains a promising renewable source of electricity generation along the coast. However, it was 
recommended to have high-quality wind data for different locations and altitudes to better estimate wind resources [35].

In northern Mexico, wind power was assessed using 237 different meteorological stations within Sonora, Chihuahua, Coahuila, Nuevo León, and Tamaulipas. To map the average monthly wind speeds in these states, an interpolation was implemented using the Kriging method. The analysis indicated that Tamaulipas is the state with the highest power density, and Nuevo León presents a large part of its territory with a power density of more than $230 \mathrm{~W} / \mathrm{m}^{2}$ [36].

In the Yucatan Peninsula, Gulf of Mexico, wind speed distribution is bimodal at lower heights. Researchers studying this region compared the results from the Weather Research and Forecasting Model (WRF) with measured data, and they concluded that mesoscale simulations may serve as a preliminary wind resource for a coastal region with low-lying areas [37].

The above-mentioned review offers several insights, including Mexico's opportunity to use wind energy for electricity generation, the importance of resource assessment analysis, and the diversity of methodologies for estimating power production. However, according to the literature, there have been no studies implemented in Mexico that present a techno-economic analysis of wind power technologies for either large or domestic applications. Also, a common issue among the works presented is the lack of reliable data sets available to use in the validation of resource assessment analyses.

In Mexico, regulatory actions have been implemented by its government through the so-called "Energetic Reform" since 2013, and the objectives include strengthening the energy sector, improving costs, attracting investment, and protecting the environment by promoting the use of clean energy sources, such as renewables, for electric generation. In particular, wind power plays a vital role due to wind potential. The potential installed capacity has been estimated to be 158,000 MW for a conservative scenario that includes high potential zones and a distance from the transmission grid of less than $10 \mathrm{~km}[38,39]$. Figure 1 presents the evolution of the wind power capacity installed over the years, as well as a projection for 2030. For the development of the wind power sector, defined goals for 2020 and 2030 target an installed capacity reaching 9934 and nearly 15,000 MW, respectively.

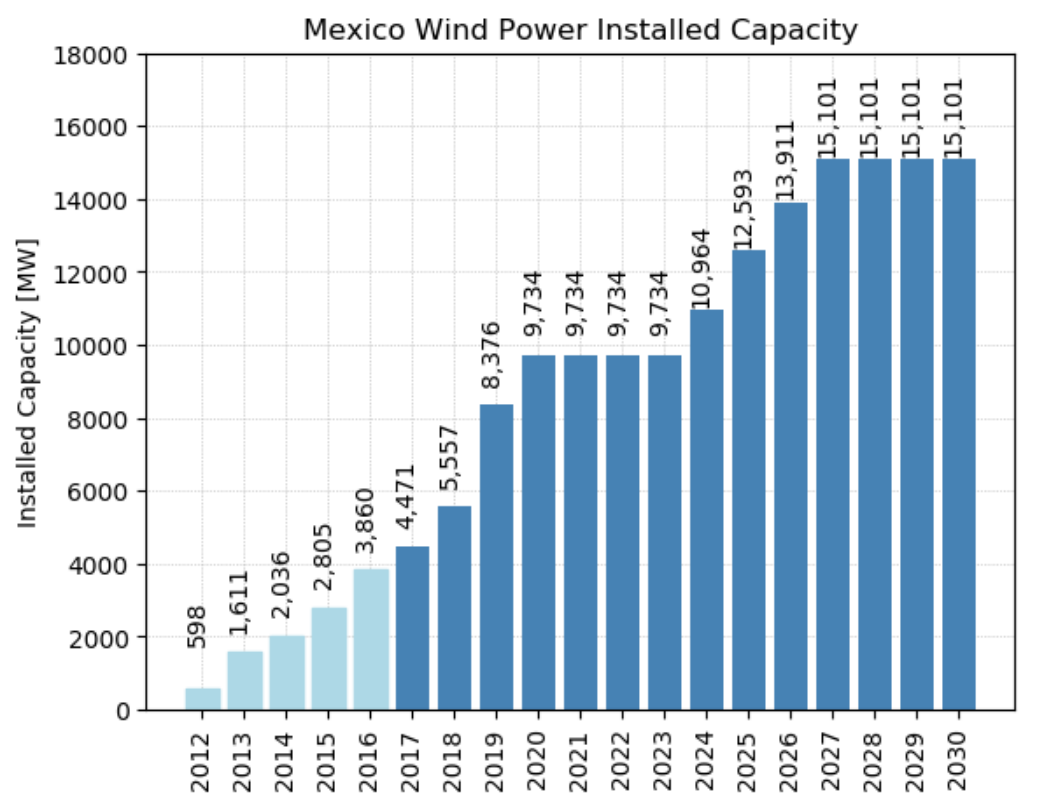

Figure 1. Wind power installed capacity over the years in Mexico. Light blue represents current information, and dark blue indicates the Mexican government's projection from 2019 to 2030. The goal is to reach $15,101 \mathrm{MW}$ in 2030 , which translates to installing approximately 4 times the 2016 installed capacity.

Furthermore, the Wind Power Techno-logic Route Map (WPTRM) [30] highlights two areas of wind power with high development potential: off-shore applications and distributed generation 
through small wind turbines. Both of them present significant opportunities for research and technological development.

There are not documented applications of distributed generation through small wind turbines in Mexico; the viability of this technology is assumed on the basis of the potential zones for large wind turbines. However, specialized studies are needed to estimate the real potential, select the appropriate technology, and analyze the technical and economic parameters that will facilitate the implementation of small wind turbine projects. These efforts, complemented by policies and strategies that promote technological development, contribute to the reducing costs, and this makes small wind turbine applications a competitive alternative to photovoltaic systems.

In this work, we developed the first approach to estimating resource assessment in a Mexican region that is monitored by an array of 18 meteorological stations. For each location, estimations of the annual energy produced (AEP) for a set of 28 SWTs were obtained from [40], with nominal powers ranging between 0.3 and $3.5 \mathrm{~kW}$, which is suitable for low wind speed conditions. These power assessments were adjusted according to the mean time of the wind speed time series used. The results, complemented by economic parameters, were used to apply the economic model, which was adapted to the Mexican electrical tariff context for a domestic user. Finally, an analysis of the technical and economic variables that influence project feasibility is presented.

This work is organized as follows. First, a description and analysis of the wind speeds used in this study are presented for each location of the meteorological stations. Next, the technologies selected for the study are presented, and the rationale for establishing the AEP using the mean time of the wind speed used for the resource assessment is discussed. Finally, the economic model, the parameters used, and the analysis of the technical and economic factors that influence the feasibility of the SWT projects at the study location are described. Each section presents the theoretical framework, methodology, results, and discussion. Finally, the general conclusions of the work are summarized.

\section{The Valley of Mexico Metropolitan Area (VMMA)}

Urban areas are especially vulnerable to climate change, and energy is one of the economic sectors that should be developed to facilitate the adaptation of such areas [41]. Moreover, $80 \%$ of greenhouse gas emissions are generated by cities. The main issues associated with increasing emissions are discussed in [42]; two of the main challenges to sustainable development in cities are transport and building energy consumption. These problems may be addressed by the integration of renewable energy sources. Technologies that are studied for their contribution to the sustainable development of cities are transport electrification and the integration of renewable energy sources into edifices to act as electricity suppliers [43]; implementing these measures would result in significant mitigation of greenhouse gas emissions [44].

The Valley of Mexico Metropolitan Area is not exempt from urban troubles, with a population of approximately 24 million people and a continuously increasing energy demand. In 2014 alone, fossil fuel consumption reached 543 PJ [45], with almost $60 \%$ used in the transport sector. Consequently, one of the main problems studied in the past 20 years has been air pollution, which is a significant issue because high and sustained exposures have important repercussions for public health [46].

The particular air quality conditions in the VMMA prompted the local government to construct a permanent program: namely, the Automatic Network of Atmospheric Monitoring (ANAM). Since 1987, ANAM has measured and recorded air composition and meteorological variables on an hourly basis through a network of over 40 monitoring sites. Data have been available on the corresponding website since 2004, and it has been a source of information related to factors such as air composition and public health [47].

In wind power resource assessment, wind speed data sets are crucial for determining power production. Previous work showed that there exists a relation between the AEP and the time used to calculate the mean ensemble of the wind speed time series [21]. That work concluded that for the same small wind turbine, there was an estimated difference of about $17 \%$ between the AEP calculated with a 
mean time of $1 \mathrm{~min}$ and that calculated using a 10-min mean time. Data from the ANAM database are 1-h mean ensembles; therefore, to approximate small wind turbine conditions, the difference between the AEP values calculated with 1- and 60-min mean times was estimated using the methodology presented in [21]. This difference between resource assessments is considered in the economic analysis, and its effects are quantified.

In this work, we used the wind speed data available on the ANAM website to develop a wind power resource assessment for 28 SWTs at 18 different urban zone sites. The presented methodology accounted for wind speed conditions and the particular electric tariff for a home user in the VMMA that was determined according to the annualized worth of the project.

Firstly, the VMMA context is presented, wind speeds and the electrical tariff are described, and the customer point of view is established in order to set forth the information required to implement the economic methodology. Thereafter, the methodology used for calculating wind power resource assessment is described, followed by a description of certain considerations for a first approach to the particular context of SWT power production and the available wind speed data. Finally, the analysis and results are presented for each section, and the main conclusions are subsequently discussed.

\section{Wind Speeds in VMMA}

The VMMA wind speed characteristics are described on the basis of data available from the ANAM program. Firstly, the geographic locations of the meteorological stations selected are presented; next, data characteristics are described according to statistical analyses that were conducted. The theoretical framework and analysis are also presented within the section.

\subsection{Data Characteristics}

In this section, the wind speed conditions in the VMMA are characterized. The data used were measured and recorded by the ANAM program. This meteorological system consists of 28 weather stations distributed within the valley; it measures and records meteorological variables, including radiation and suspended particles, and provides an air quality index.

Wind speed data have been available since 1994 for certain locations. However, in order to calculate power resource assessments, a period of 3 years was selected: 2012, 2013, and 2014. These years were selected due to the data availability and time series integrity; following the selection, analysis of the data availability was conducted. It should be noted that, because of the required data quality, of the 28 stations, only 18 were selected for carrying out the analysis. In Figure 2, the locations of the meteorological stations are illustrated. At each site, 28 SWTs were assessed in order to determine their techno-economic feasibility.

Data availability is a significant issue in wind power resource assessment. In Table 1, the percentages of data that were available for the selected period are presented. It can be seen that 13 of the sites had between $80 \%$ and $100 \%$ of their wind speeds available, 3 sites had between $60 \%$ and $80 \%$, and only 2 had a $50 \%$ availability. This means that, for the last two cases, 1.5 years of data were used for calculating the annual energy produced, a parameter used in the economic analysis.

Wind speed is an important meteorological variable for understanding air pollution behavior. Therefore, several analyses have been carried out to study wind circulation patterns and their origins at the mesoscale in Mexico City and its surroundings [48-50]. Within this context, the aim of wind speed characterization is to fit a statistical model that represents wind speed behavior at each location. This is then used to calculate the AEP and, therefore, to determine the techno-economic feasibility of SWTs.

Wind speeds obtained from meteorological stations were recorded with a 1-h mean time. As the first element of analysis, in Figure 3, the wind speed time series of every site over a 5-day period are plotted. This selected period serves the purpose of observing the wind speed behavior throughout the day. Similar wind conditions are observed over time, and the maximum and minimum values may be associated with day and night cycles. 


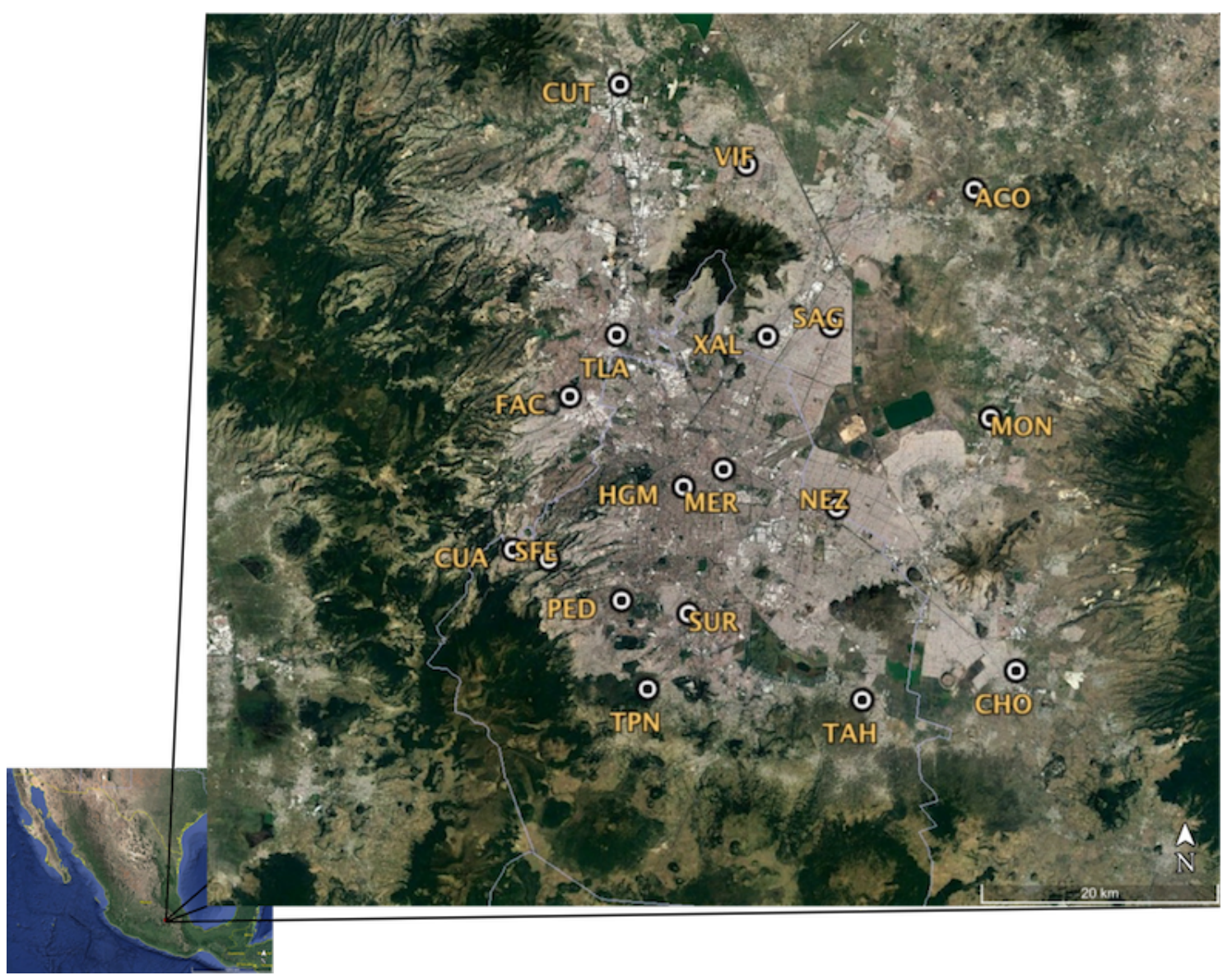

Figure 2. Locations of 18 meteorological stations selected to calculate wind power resource assessments. Names and nomenclature used: Acolman (ACO), Chalco (CHO), Cuajimalpa (CUA), Cuautitlán (CUT), FES-Acatlán (FAC), Hospital General de México (HGM), Merced (MER), Montecillo (MON), Nezahualcóyotl (NEZ), Pedregal (PED), San Agustín (SAG), Santa Fe (SFE), Santa Úrsula (SUR), Tláhuac (TAH), Tlalpan (TPN), Tlalnenpantla (TLA), Villa de las Flores (VIF), and Xalostoc (XAL) (extracted from Automatic Network of Atmospheric Monitoring (ANAM) data).

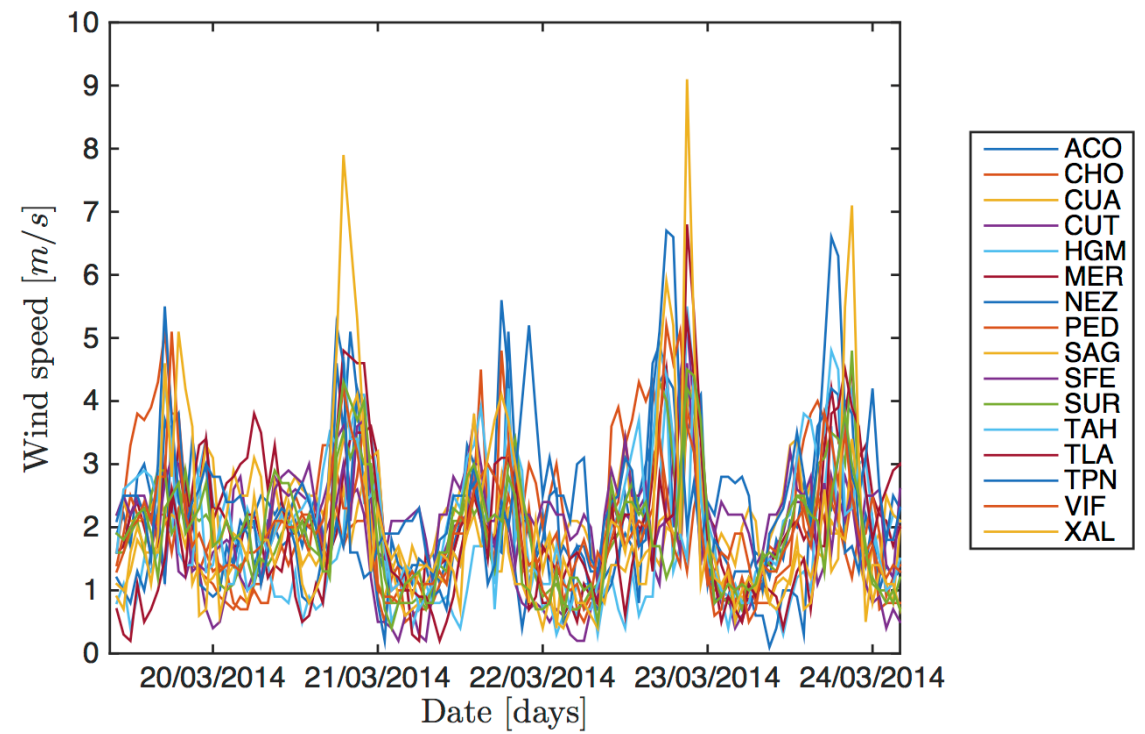

Figure 3. As the first element of analysis, the time series of the locations studied are plotted. Similar behavior is observed over time in all locations, and the maximum and minimum values may be associated with day and night phenomena. 
Table 1. Percentage of data available for every selected meteorological station for 2012, 2013, and 2014. In the specific case of the station $X A L$, the average data available were calculated considering only 2013 and 2014.

\begin{tabular}{|c|c|c|c|c|c|c|c|c|c|c|c|c|c|c|c|c|c|c|}
\hline Year & ACO & $\mathrm{CHO}$ & CUA & CUT & FAC & HGM & MER & MON & NEZ & PED & SAG & SFE & SUR & TAH & TLA & TPN & VIF & XAL \\
\hline 2012 & 96 & 98 & 96 & 60 & 99 & 71 & 100 & 61 & 44 & 99 & 93 & 77 & 100 & 59 & 82 & 91 & 97 & - \\
\hline 2013 & 96 & 97 & 94 & 91 & 97 & 72 & 100 & 50 & 44 & 97 & 97 & 99 & 99 & 97 & 88 & 91 & 99 & 40 \\
\hline 2014 & 79 & 97 & 88 & 86 & 92 & 45 & 99 & 42 & 76 & 96 & 90 & 99 & 99 & 94 & 84 & 92 & 99 & 83 \\
\hline
\end{tabular}

\subsection{Statistical Model}

The determination of an appropriate statistical model or probability density function (PDF) to represent wind speed conditions is an important step in resource assessment. An extensive catalog of PDFs is presented in [51]; however, a common approach is to select Rayleigh or Weibull PDFs as statistical models [52-54]. Rayleigh is known to be a particular case of the Weibull PDF, and while the latter offers greater flexibility for fitting an experimental data set, a Rayleigh PDF is commonly used for its simplicity. In this work, due this characteristic and as a first approach, the Rayleigh PDF was selected to represent the wind speed data conditions at the different assessed sites. In order to demonstrate PDF reliability, a goodness-of-fit criterion was applied, as discussed in a later section.

The Rayleigh PDF for an aleatory variable $x$ is defined by Equation (1). The corresponding cumulative distribution function $C D F$ is provided by Equation (2):

$$
\begin{gathered}
p(x)=\frac{\pi}{2}\left(\frac{x}{\bar{x}^{2}}\right) \exp \left[-\frac{\pi}{4}\left(\frac{x}{\bar{x}}\right)^{2}\right] \\
F(x)=1-\left[\exp -\frac{\pi}{4}\left(\frac{x}{\bar{x}}\right)^{2}\right],
\end{gathered}
$$

where $\bar{x}$ represents the sample mean; in this work, the random variable is the wind speed $u$. This characteristic allows for fitting a statistical model using the simply calculated arithmetic mean. Probability plots were developed in order to determine the goodness of fit between the statistical model and each wind speed data set. Figure 4 presents the Rayleigh distribution histograms and probability plots of two locations, TPN and FAC. These locations represent the extreme scenarios for goodness of fit among all locations. The first scenario is observed for the location TPN; the model partially represents the data. As observed in the top-right graph, the wind speed values from 0 to almost $4 \mathrm{~m} / \mathrm{s}$ behave similarly, but there are differences for the higher wind speeds. Overall, the Rayleigh distribution represents $90 \%$ of the data correctly. The second scenario is one in which the model well represents all wind speeds, which is observed for the location FAC (in the bottom-right graph). All other locations in this study present behaviors that are between the two extreme scenarios described.

All Rayleigh PDF models for the different locations are presented in Figure 5 for the purpose of comparing statistical models. In Table 2, the statistical parameters $\alpha, \bar{u}, \mu$, and $\sigma$ are reported and represent the PDF shape parameter, arithmetic mean, expected model value, and model dispersion, respectively. The expected wind speed values are observed to be between 1.6 and $2.8 \mathrm{~m} / \mathrm{s}$, while the dispersion parameters are almost $1 \mathrm{~m} / \mathrm{s}$, with the exception of $\mathrm{XAL}$, where larger values are obtained.

At this point, wind speeds in the VMMA were characterized, and similar expected values were calculated. As a statistical model was selected to represent site conditions, the following section presents the economic context of the electric feeds in the site under study. 

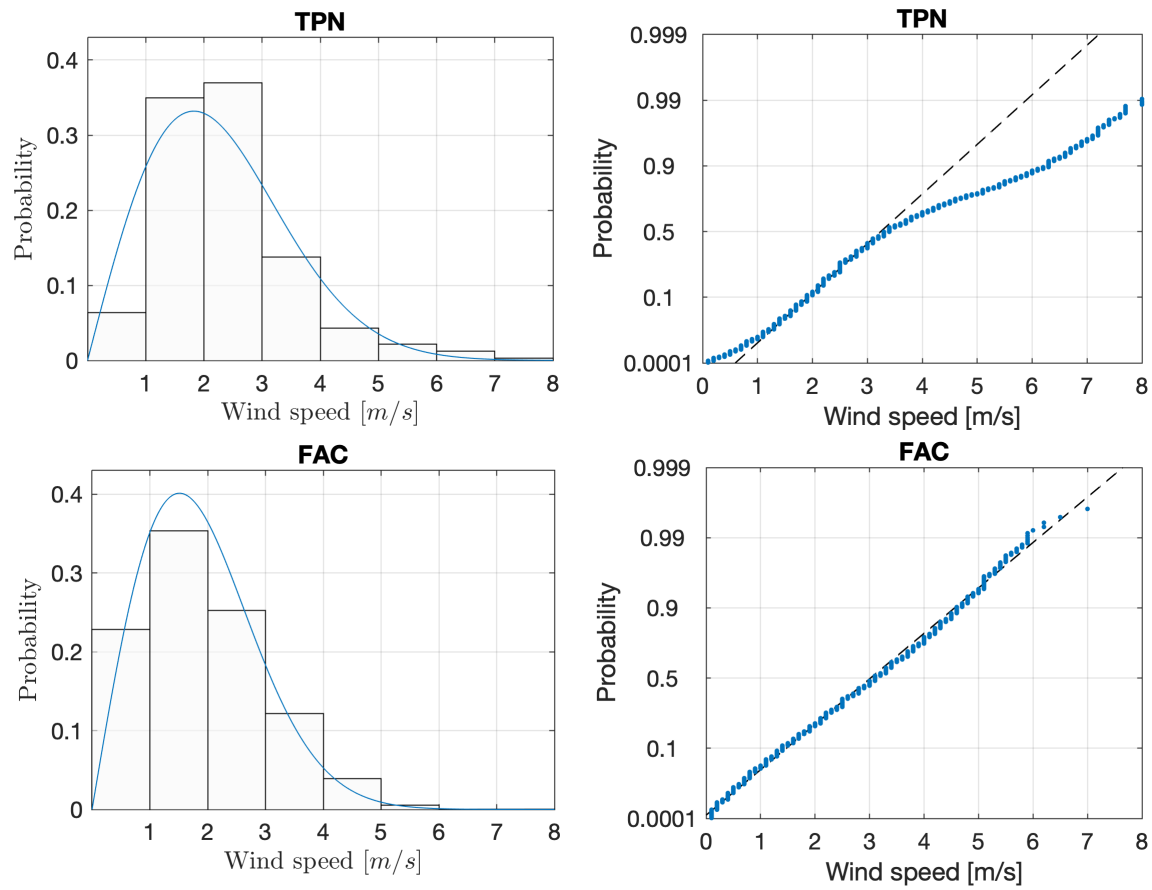

Figure 4. Rayleigh probability functions were fitted to every anemometric station in order to verify the adequate model representation. Probability plots were developed between the cumulative distribution function $(\mathrm{CDF})$ and real data. Due the large number of locations, two typical plots obtained among the sites were selected to illustrate the goodness-of-fit criterion.

Table 2. Parameters of statistical models fitted to each anemometric station. In the first column, $\alpha$ corresponds to the Rayleigh parameter, $\bar{u}$ represents the arithmetic mean, $\mu$ is the expected value of the probabilistic distribution, and $\sigma$ is the dispersion parameter.

\begin{tabular}{|c|c|c|c|c|c|c|c|c|c|c|c|c|c|c|c|c|c|c|}
\hline Location & ACO & $\mathrm{CHO}$ & CUA & CUT & FAC & HGM & MER & MON & NEZ & PED & SAG & SFE & SUR & TAH & TLA & TPN & VIF & XAL \\
\hline$\alpha$ & 1.95 & 1.71 & 1.62 & 1.31 & 1.51 & 1.56 & 1.71 & 1.78 & 1.90 & 1.53 & 1.50 & 1.79 & 1.61 & 1.67 & 1.64 & 1.83 & 1.57 & 2.23 \\
\hline $\bar{u}$ & 2.35 & 2.05 & 2.10 & 1.59 & 1.85 & 1.87 & 2.15 & 1.97 & 2.25 & 1.95 & 1.87 & 2.31 & 2.01 & 2.07 & 2.01 & 2.33 & 1.93 & 2.52 \\
\hline$\mu$ & 2.45 & 2.15 & 2.03 & 1.65 & 1.89 & 1.95 & 2.14 & 2.23 & 2.38 & 1.91 & 1.88 & 2.24 & 2.01 & 2.10 & 2.05 & 2.29 & 1.97 & 2.79 \\
\hline
\end{tabular}

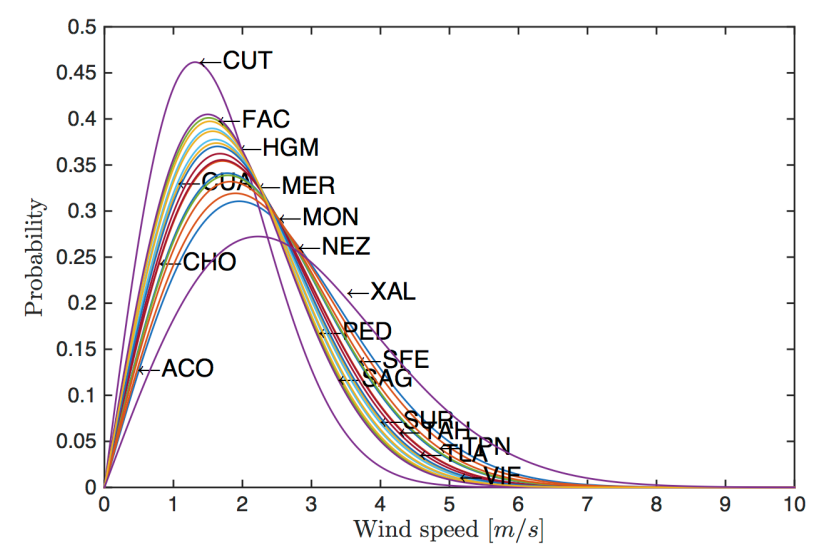

Figure 5. Rayleigh probability distributions fitted to each analyzed site.

\section{Power Resource Assessment for Small Wind Turbines}

In the previous section, wind conditions were described by means of a statistical model. Here, certain considerations for the estimation of wind power resource assessment for the specific case of the SWT are presented. Firstly, its nominal capacity is defined in the context of this work; then, a theoretical framework is presented for estimating its electric production in specific wind conditions, 
and, finally, the implications of using different wind speed data sampling times to estimate energy production are discussed.

\subsection{Wind Power Resource Assessment for Small Wind Turbines}

There is no global standard classification for SWTs; however, for the purpose of this work, we define an SWT as that which may meet the electric demand of a home and has physical dimensions that permit its easy installation by a domestic user. These specific conditions are satisfied by SWTs with nominal powers between 0.3 and $3.5 \mathrm{~kW}$.

Resource assessment methodologies have been widely documented in the basic literature in the field [55]. The main purpose of such an assessment is to estimate the annual energy production (AEP) of a wind turbine for specific wind conditions, and it is an essential parameter for conducting the economic analysis. Resource assessment is based on a statistical approach in which the wind speeds $u$ are represented by a PDF $f(u)$, and a PDF is fitted to a wind speed data set to represent the site wind speed conditions. Data $u_{i}$ or statistical models may be used to estimate electric generation $E_{w}$ or mean power generated $\bar{P}$ for a period of time $\Delta t$ in combination with the power curve $p_{w}(u)$ of the wind turbine selected, using Equation (3) or (4), respectively.

$$
\begin{gathered}
E_{w}=\sum_{i=1}^{N} p_{w}\left(u_{i}\right) \Delta t \\
\bar{P}=\int_{0}^{\infty} p_{w}(u) f(u) d u
\end{gathered}
$$

Wind velocities should have specific characteristics in order to conduct a resource assessment: they must be measured and recorded by an anemometer with uncertainties of $1 \%$ or $2 \%$, sampled at 1 or $2 \mathrm{~Hz}$, and averaged by periods of $10 \mathrm{~min}$. Furthermore, measurements are recommended to be extracted from a period ranging from 1 year to 10 years, bearing in mind that more extensive data sets provide more accurate results [9]. However, it is not economically feasible to follow this common methodology for wind power resource assessment calculations in the specific case of an SWT for a domestic application due of the complexity of the environments and the high-resolution data $[9,56]$, as well as the technical inadequacy, as discussed later.

Previous work has described the effects of using different mean times in wind power resource assessments [21]. It was observed that using larger mean times leads to an underestimation of the energy produced. This effect should be considered since the data obtained from the ANAM site were averaged over time periods of $1 \mathrm{~h}$. In the following section, we discuss how to estimate these effects on the AEP.

\subsection{Difference in Resource Assessments: 1-min and 60-min}

The data used to develop wind power resource assessments consist of wind speeds that were hourly averaged. As stated in the previous section, power estimations may be undervalued as a result of using larger mean times in wind power resource assessments. This becomes more relevant in the current context since SWTs present small inertia constants, so changes in wind speed have a greater impact on energy production than in large wind turbines.

A first approach to modeling wind turbine dynamics can be developed from a Lagrangian perspective, in which particular dynamics are modeled, although this type of analysis is constructed for conservative fields. The wind turbine may be considered as a rotating ideal rigid body with an external constructive force that is proportional to the velocity in a generalized coordinate system $q$ and $\lambda$ a constant, as described by Equation (5):

$$
\frac{\partial L}{\partial q_{j}}-\frac{d}{d t} \frac{\partial L}{\partial \dot{q}}=\lambda|\dot{q}|^{n}
$$


For a rotating system with angular moment $I$, radius $R$, mass $m$, potential energy equal to zero, and an external force $F$ proportional to the rotational speed $\dot{\theta}, F=\lambda \dot{\theta}$, Equation (5) can be expressed as

$$
I \ddot{\theta}=\lambda \dot{\theta},
$$

where $L=T-U$, and $T$ and $U$ represent the potential and kinetic energy of the system, respectively. Therefore, the dynamic description is provided by Equation (7):

$$
\theta(t)=C_{1} e^{\frac{2 \lambda}{m R^{2}} t}+C_{2} .
$$

Equation (7) is clearly defined by two physical parameters of the wind turbine: radius and mass. These parameters determine the dynamic response of the system under the same forces, as generated by the variable wind speeds. If $v=\frac{2 \lambda}{m R^{2}}$ is the characteristic parameter, we can say that

$$
v \sim \frac{1}{R^{2}}
$$

If we consider two wind turbines with radii $R_{1}>R_{2}$, then $v_{1}<v_{2}$, and their characteristic times will therefore be $t_{R 1}>t_{R 2}$. This heuristic model provides initial insight into the dynamic system response and enforces the fact that small turbines respond faster than large ones.

The objective of this work is to analyze the feasibility of using SWTs for power generation and to describe the physical environment in which an SWT produces energy. The 1-min mean time is suitable to describe the wind speed time series since it takes into account the information related to gusts that may contribute to an improvement in power production [21].

Therefore, using the data and following the methodology presented in [21], we calculated the difference between power estimations using 1- and 60-min mean times for three SWTs, the results of which are presented in Figure 6. A larger difference between resource assessments can be observed near $30 \%$, corresponding to power estimations of 1 and $60 \mathrm{~min}$. It can also be seen that differences among SWTs are not significant.

As complementary information, in Figure 6, we also present the percentage differences between power estimations calculated from data samples with 5- and 10-min mean times, and all results are compared.

The percentage difference calculated among the power estimations can be explained by the amount of data filtered in the mean calculus. Figure 7 presents the time series of the 1- and 60-min mean times, and it is observed that certain information is lost by the mean calculus. For example, the maxima values in the 1-min time series are not observed in the 60-min series, and a larger data dispersion is also observed for the 1-min time series.

This work is oriented toward conducting a resource assessment for SWTs in domestic applications; therefore, the influence of wind speed mean times on the resource assessment and the 1-h mean time of the ANAM data were taken into account. We considered that the amount of energy underestimated is at least $30 \%$, and this difference was added to the AEP calculated from the $1 \mathrm{~h}$ time series to approach the power production of an SWT.

Having presented the methodologies for estimating the AEP and the considerations in approaching the energy generated by an SWT, in the following section, we describe the conceptual framework for developing the techno-economic assessment. 


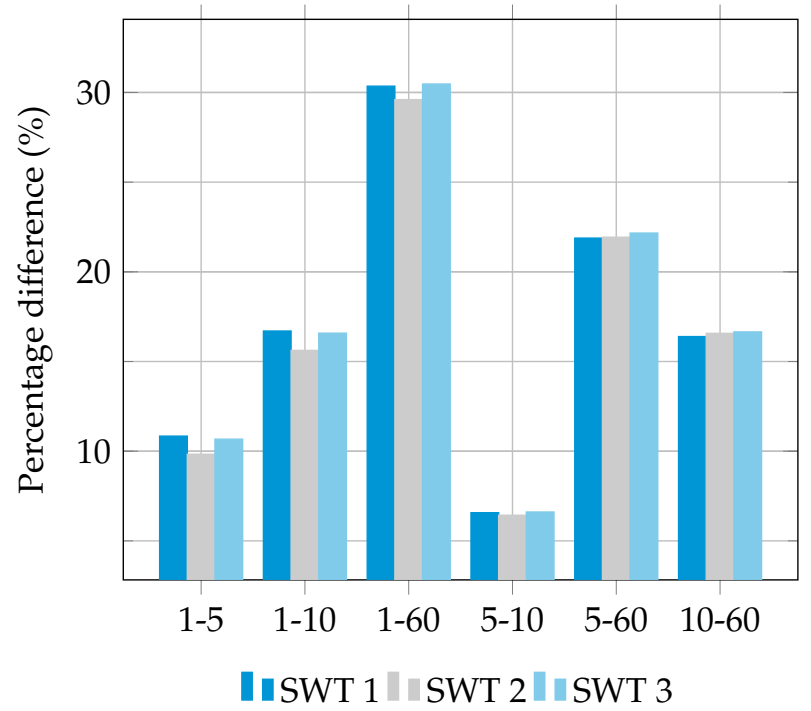

Figure 6. Wind power production was calculated for three (SWTs) and time series using mean times of $1,5,10$, and $60 \mathrm{~min}$. Then, the difference between resource assessments was calculated for different mean times. The 1-5 label represents the difference between the 1- and 5-min assessments, and so on for the remainder of the time series. It is observed that the percentage depends mainly on mean times, but the differences due to the SWT model are not significant. The largest percentage difference is approximately $30 \%$ and corresponds to the 1 - and 60-min assessments.

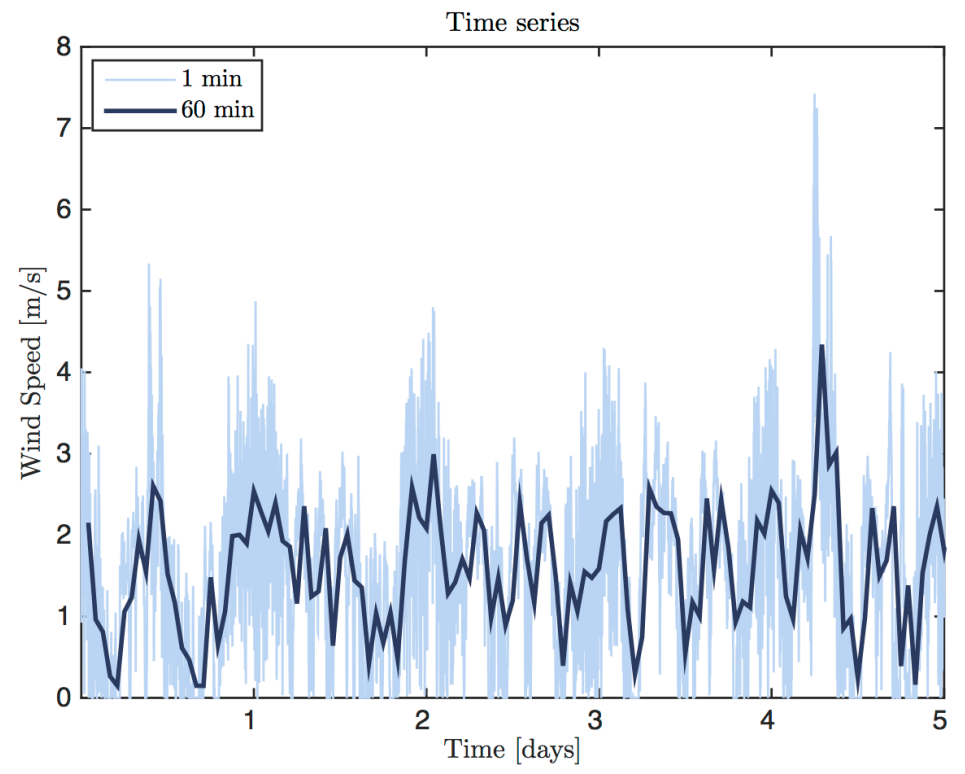

Figure 7. Time series of 1- and 60-min mean times in light and dark blue, respectively. A larger amount of information is observed in the 1-min time series; for example, the maxima values in the 1 -min time series are not observed in the 60 -min series. These differences produce underestimations in resource assessments.

\section{Techno-Economic Assessment}

The economic analysis of a project consists of predicting its incomes and expenses and thus the viability of the investments. These analyses also provide useful economic information when it is necessary to determine the most preferable alternative among different technologies. Examples of these methodologies applied to wind power projects can be found in $[57,58]$. Various methods exist in the literature that can aid in such decisions. All of them consider the following as elements of study: 
the value of money over time, annual cash flows that comprise incomes and expenses, and project lifetime, which must be comparable if the alternatives have different lifetimes [59].

The change in money's worth over time is modeled as follows. Given a single payment at a future worth $F_{w}$ in year $n$, a present worth $P$ with a discount rate $i$ can be calculated by Equation (9):

$$
P=F_{w} \frac{1}{(1+i)^{n}}
$$

Thus, a project can be analyzed by applying a cash flow model, where the annual incomes and expenses during the project lifetime of $n$ years are solved to determine the present worth. The simplest model considers the initial cost per $\mathrm{kW}$ installed, represented by $I C$; constant annual cash flows related to benefits $B_{A}$; and operation and maintenance costs $O \& M_{A}$. At the end of the project, the salvage value $S$ is the final income projected. A typical cash flow diagram is presented in Figure 8.

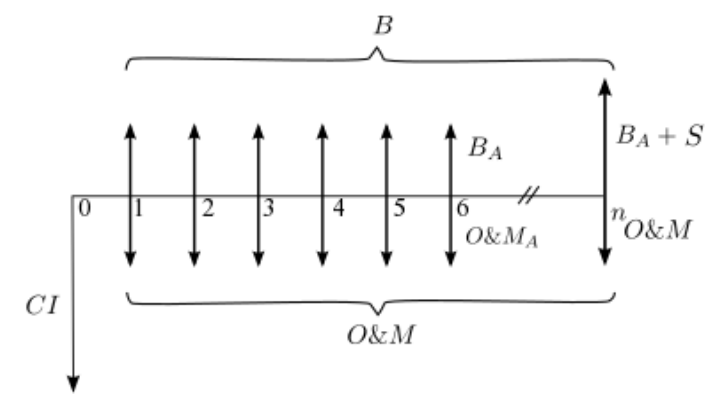

Figure 8. Typical cash flow of a wind power project. IC represents the initial investment, which is composed of the wind turbine costs and is related to the installation. $B_{A}$ represents the annualized economic benefits produced by the sale of electricity. The annualized operation and maintenance costs are denoted by $O \& M_{A}$. Finally, in the final year of the project, extra income known as the salvage value $S$ is considered.

The net present value $\left(N P V_{T}\right)$ of a renewable energy project is a common economic parameter that allows for the development of an economic analysis and determination of its feasibility. Two economic components are identified in the $N P V_{T}$ of a wind energy project: the income, which contains the annual profits due to electricity sales $N P V\left(B_{A}\right)$ and a salvage value $N P V(S)$ at the end of the project; and the expenses, composed of the initial investment $I C$ and annual operation and maintenance costs $O \& M_{A}$.

$$
N P V_{T}=\left[N P V\left(B_{A}\right)+N P V(S)\right]-\left[I C+N P V\left(O \& M_{A}\right)\right]
$$

In this analysis, the selected SWTs have different lifetimes, which is a common problem when different technologies are compared. In order to enable comparison, the annual worth is selected as the method of analysis, which converts the typical cash flow described previously into annual equally valued flows (ANPVs). To apply these criteria, the original cash flows are first converted into a single $N P V_{T}$ using Equations (9) and (10); then, the $A N P V s$ are calculated using Equation (11).

$$
A N P V=N P V_{T}\left[\frac{i(1+i)^{n}}{(1+i)^{n}-1}\right]
$$

After describing the economic model, the next step is to determine each of its defining parameters. Firstly, the initial costs IC are described. This parameter takes into account all costs related to installing an SWT, including the electrical infrastructure, conditioning and grid integration, installation, and civil works. The variable is commonly presented as the coefficient of the initial investment cost and the capacity installed $[\$ / \mathrm{kW}]$. In Figure 9, the initial costs of a small wind energy project are presented, with different nominal powers from 2012 to 2015 [7]. It is observed that the initial costs are reduced 
when higher nominal power is used. In this context, the installation cost that was used in the economic analysis in this work is $\$ 6040.00 \mathrm{USD} / \mathrm{kW}$.

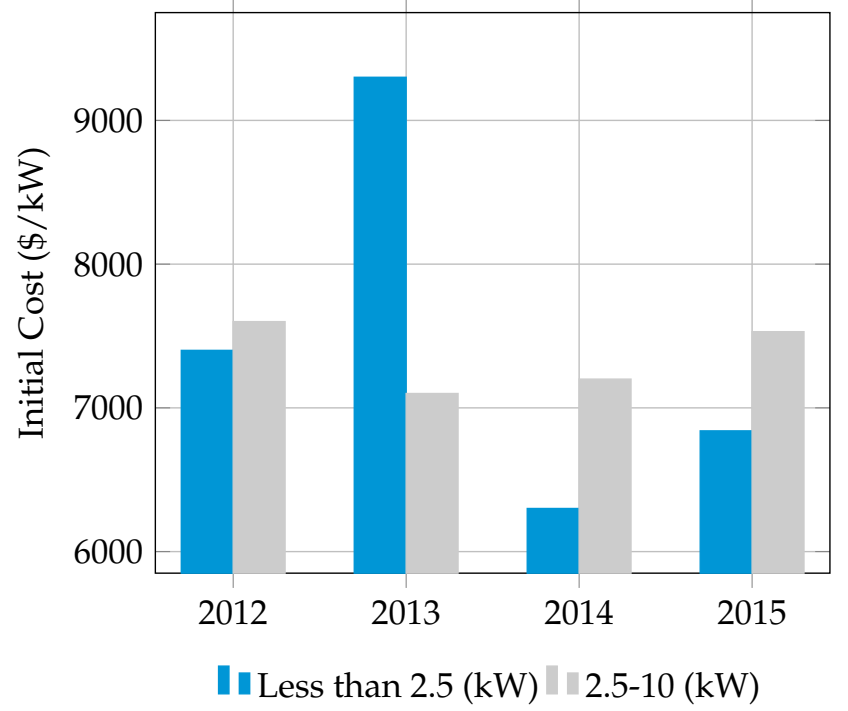

Figure 9. Initial costs for different installed capacities from 2012 to 2015.

The annual benefits $B_{A}$ of the project are considered to be proportional to the AEP and are represented as constant annual cash flows. In Mexico, a domestic user cannot sell energy under the current legal framework. The commercialization scheme is conducted through the exchange of electrons. The domestic renewable energy producer injects its generation into the grid and, when necessary, extracts energy; then, a final balance is calculated at the end of the period. Therefore, the benefits are actually savings that are reflected in electric billing. In order to estimate the savings for a domestic user, it is necessary to know the energy costs, which may not reflect its real generation cost due the subsidy scheme for domestic users in Mexico for certain electricity tariffs.

The cost per $\mathrm{kWh}$ is associated with the seasonal and geographic mean temperatures within Mexico, and billing for electric services takes place bimonthly. In the specific case of Mexico City, the cost per $\mathrm{kWh}$ for a domestic user ranges from 0.044 to $0.24 \mathrm{USD} / \mathrm{kWh}$ for demand of less than $75 \mathrm{kWh}$ to greater than $250 \mathrm{kWh}$, respectively. These tariffs are known as T1 and Domestic High Consumption (or DAC, per its abbreviation in Spanish), respectively [60]. T1 and DAC tariffs also represent the higher and lower values of the costs for domestic users. Therefore, these values were selected as the upper and lower limits for the analysis.

It should be noted that the electric domestic tariffs are subsidized in Mexico; however, when electric consumption reaches the DAC level, the tariff subsidy is eliminated, so the real cost of the energy is paid in this scenario. Furthermore, it is important to note that Mexican energy policies do not offer any incentive to include renewable systems for electric generation and/or mitigate $\mathrm{CO}_{2}$ emissions through electric generation from a renewable energy source for home users.

The Metropolitan Area is formed by Mexico City and certain State of Mexico municipalities and is home to nearly 24 million people, of which almost 6.5 million users represent the domestic feed tariff, representing 5.5 million MWh consumed in 2014 alone [61,62]. Therefore, if wind conditions are optimal, there could be a significant number of potential users of SWT systems. Thus, the present study is relevant for improving the sustainability of the city.

Therefore, the annual benefits $B_{A}$ are calculated as presented in Equation (12):

$$
B_{A}=C_{k W h} A E P,
$$

where $C_{k W h}$ is the cost of $\mathrm{kWh}$, and $A E P$ is the annual energy produced. 
The operation and maintenance costs $O \& M_{A}$ are considered to be constant cash flows during the project lifetime and, in this work, are calculated as proportional to the initial costs IC. We consider this proportionality to be $0.5 \%$ [63]:

$$
O \& M_{A}=a I C \text {. }
$$

The salvage value $S$ was calculated according to a straight-line depreciation of $10 \%$ [64]. The annual depreciation $D_{A}$ of a wind turbine with initial costs $I C$ is expressed by Equation (14):

$$
D_{A}=\frac{I C-S}{n},
$$

where $n$ is the project lifetime. In this analysis, $D_{n}$ is considered the salvage value.

\section{1. $A N P V$}

As the first elements of the economic analysis, the ANPVs were calculated for the 28 SWTs assessed at the 18 sites. The economic conditions selected are the energy costs in a DAC electric tariff. In order to estimate the annual benefits, the $A E P$ is assumed to be constant over the life of the project. The AEP was calculated using the original time series with mean times of $60 \mathrm{~min}$. As the analysis was developed for SWTs in domestic applications, 30\% additional energy was applied to the AEP as a first approach to compensating for the underestimation that arises from the sample mean time. Finally, a $3 \%$ discount rate was selected.

In Figure 10a, the calculated $A N P V s$ are plotted, represented by $\circ$, and the colors are associated with a specific $S W T$ model. The values repeated along the nominal power axis represent different wind turbine models with equal nominal power. This graphical representation was selected to visually compare the economic and technical parameters among SWTs with equal nominal power. The location axis represents the 18 studied sites in alphabetical order. It is observed that $A N P V S$ among the locations are similar, which may be explained by the similar wind conditions within the VMMA. In order to observe this behavior, the location axis is eliminated in Figure 10b.

It is observed that, for most sites, the values calculated are negative. However, there two SWTs that exhibit positive $A N P V s$, and these are interpreted as annual project incomes. Therefore, although mainly low wind speed conditions exist within the VMMA, an appropriately selected technology and elevated costs per kWh may establish a favorable context in which positive annual incomes are obtained. The nearest zero values-projects assessed with minimal annual losses-are those with SWTs having smaller nominal powers.

In order to analyze the general behavior of the calculated $A N P V$ values, SWTs with equal nominal power are grouped and plotted in Figure 11. It is observed that the two turbines with a nominal power of $0.6 \mathrm{~kW}$ exhibit low dispersion within the VMMA, which is a sign of similar economic performance. The two wind turbines with a nominal power of $2.5 \mathrm{~kW}$ present a dispersion of 800 [USD], which is the largest for the nominal power sets. Furthermore, for these SWTs, a difference between ANPVs is observed, which indicates that, despite the equal nominal power, the annual values differ by nearly 400 USD.

In order to observe $A N P V$ dispersion for a specific nominal power, Figure 12 presents the probability plots of the seven turbine models with a nominal power of $1 \mathrm{~kW}$. The wind turbines with the highest and lowest ANPVs within the VMMA are the third and fifth, respectively (From left to right). The seventh $S W T$ exhibits minimum dispersion, which may be interpreted as persistent power production at all locations.

Thus, although nominal power provides a technical characteristic for classifying wind turbines, it is observed that wind turbines with equal nominal power exhibit different economic performances. Therefore, in order to develop reliable techno-economic studies, the methodology should include a comparison of technologies with equal or similar nominal power values in order to carry out an appropriate technology selection. 


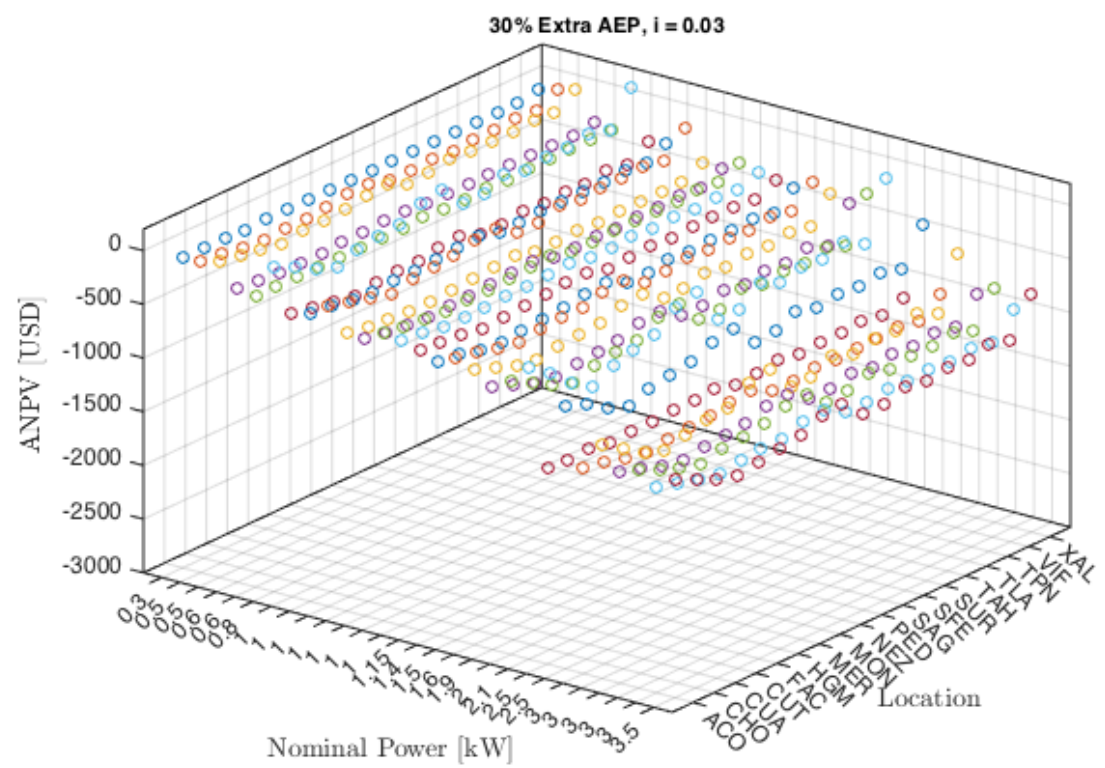

(a)

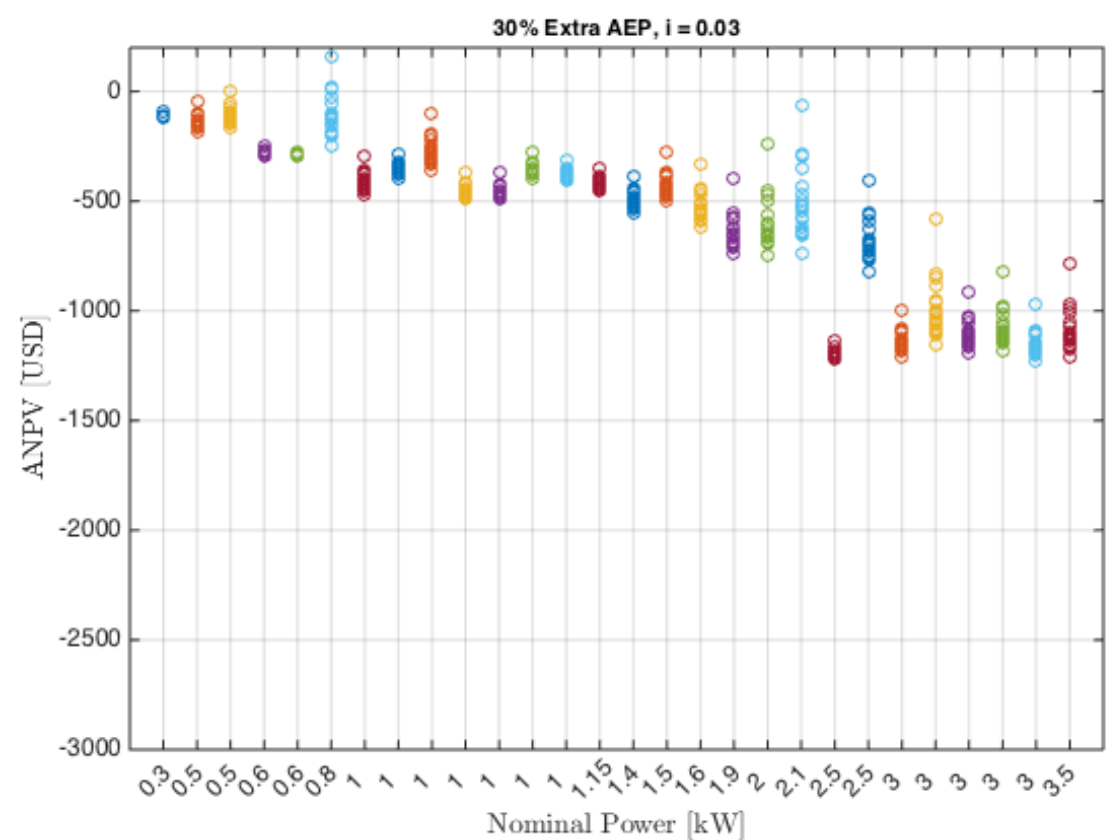

(b)

Figure 10. ANPVS are calculated for the 18 sites, where 28 SWTs are assessed. Economic conditions are as follows: cost of energy with the Domestic High Consumption (DAC) electric tariff, benefits proportional to AEP, which considers 30\% extra energy to approximate the SWT case, and a 3\% discount rate. Values repeated along the nominal power axis represent different wind turbine models with equal nominal power. (a) Annualized net present values ANPVs calculated for all sites and SWTs; (b) The location axis is removed, and similar behavior is observed for all SWTs; wind conditions appear similar within the Valley of Mexico Metropolitan Area (VMMA). 


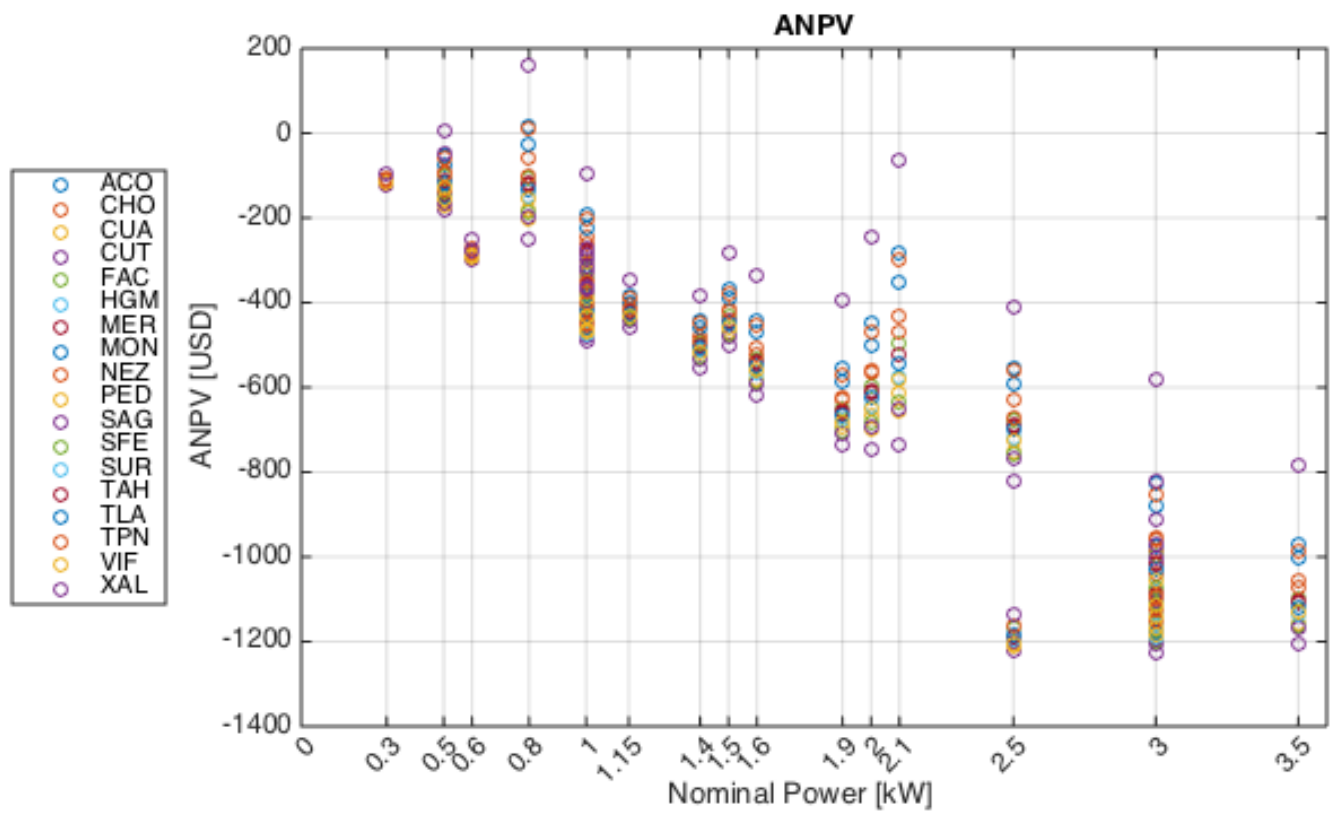

Figure 11. Turbines with equal nominal power are grouped and plotted under the corresponding values in such a way that individual $A N P V S$ may not be observed in order to analyze the existence of a global tendency.

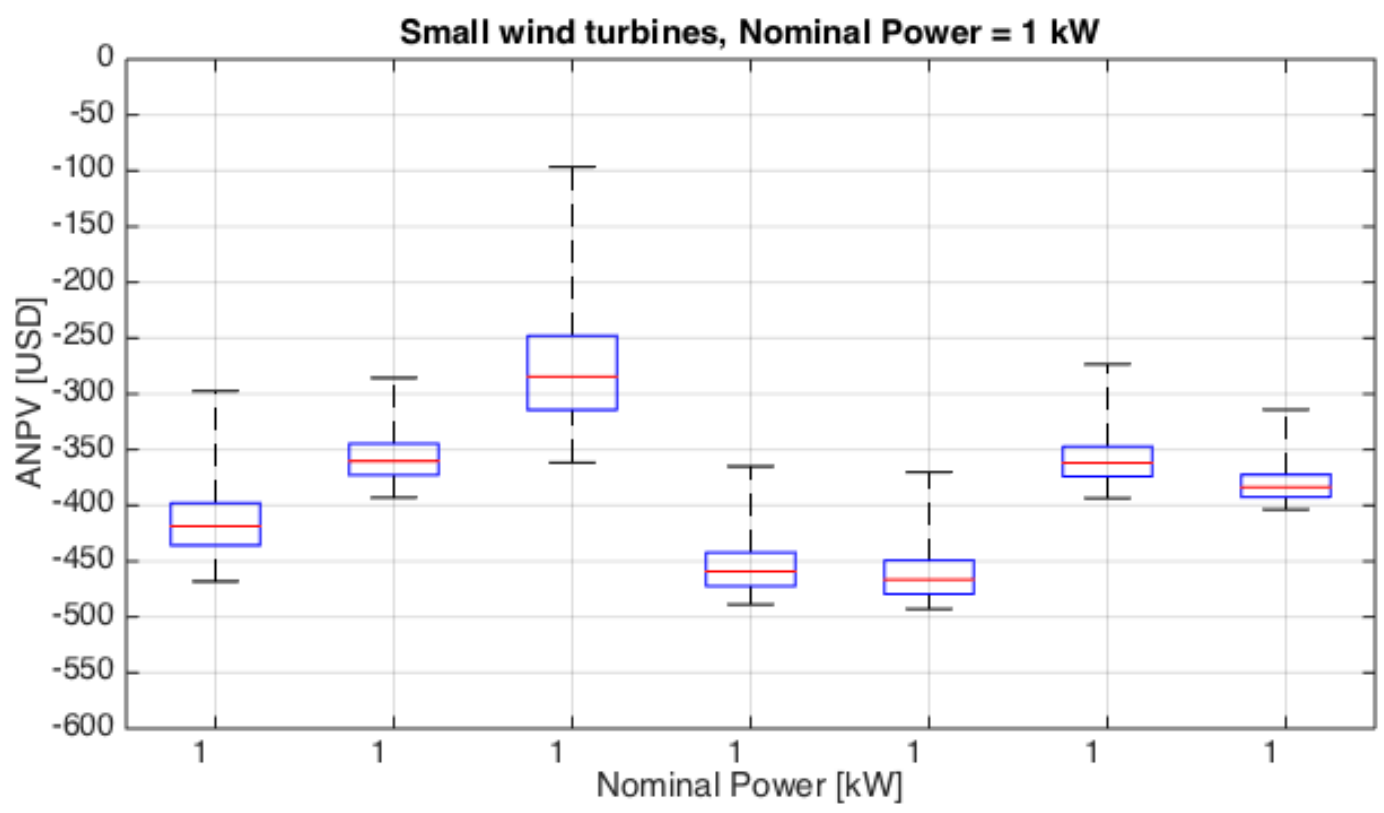

Figure 12. Here, only the seven SWT models with a nominal power of $1 \mathrm{~kW}$ are plotted. The highest and lowest data dispersion intervals observed are approximately 250 and 100 [USD], observed for the third and seventh wind turbines from left to right, respectively.

\subsection{Capacity Factor}

The capacity factor $C F$ is a common parameter used to report SWT power generation performance. It is calculated with the ratio of the real wind turbine production and the production assuming nominal generation for a period of 1 year.

Preserving the order of nominal power and sites from Figure 10, Figure 13 presents the $C F$ values for the 28 sites and 18 SWTs. It is observed that, although wind conditions are similar within the VMMA, power performance results from a relationship between the wind conditions and characteristics of the technology represented by the power curve. For example, the SWT with a nominal power of $0.8 \mathrm{~kW}$ 
exhibits a $C F$ between 5 and $31 \%$. This is one of the $A N P V s$ previously calculated with positive values. Therefore, the appropriate selection of an $S W T$ is a determining factor for defining project feasibility. This variability in $C F$ values by location and wind turbine was also observed in the Greater London area [11].

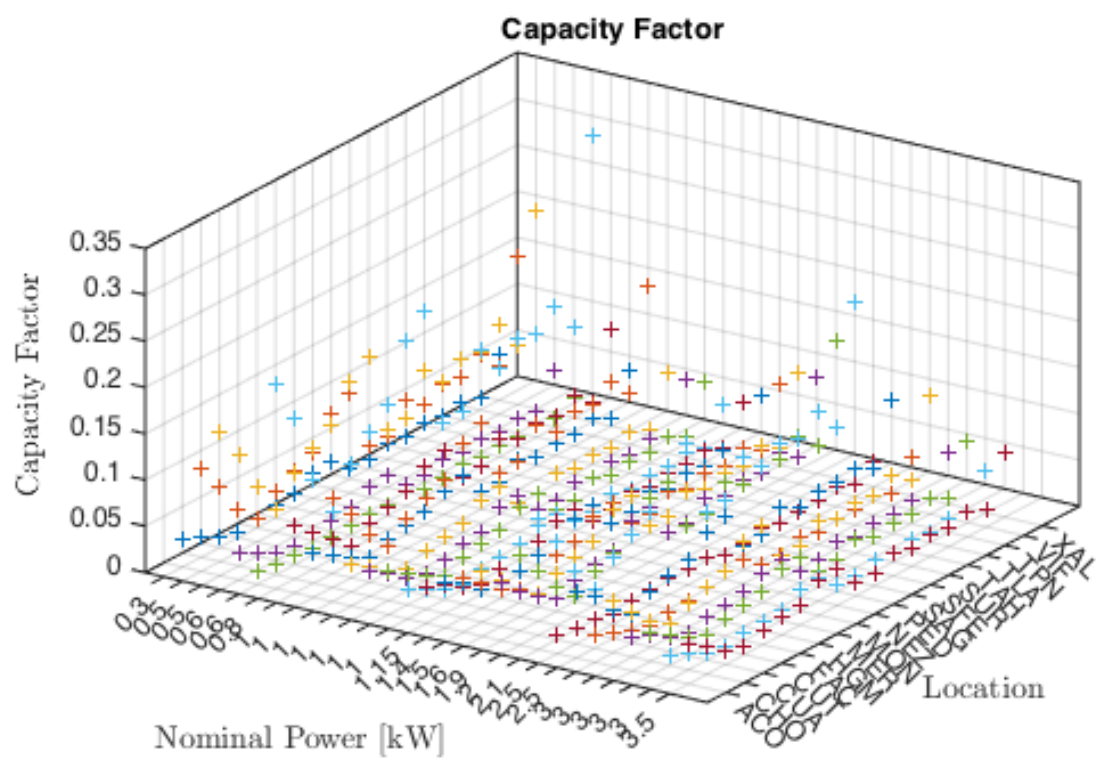

(a)

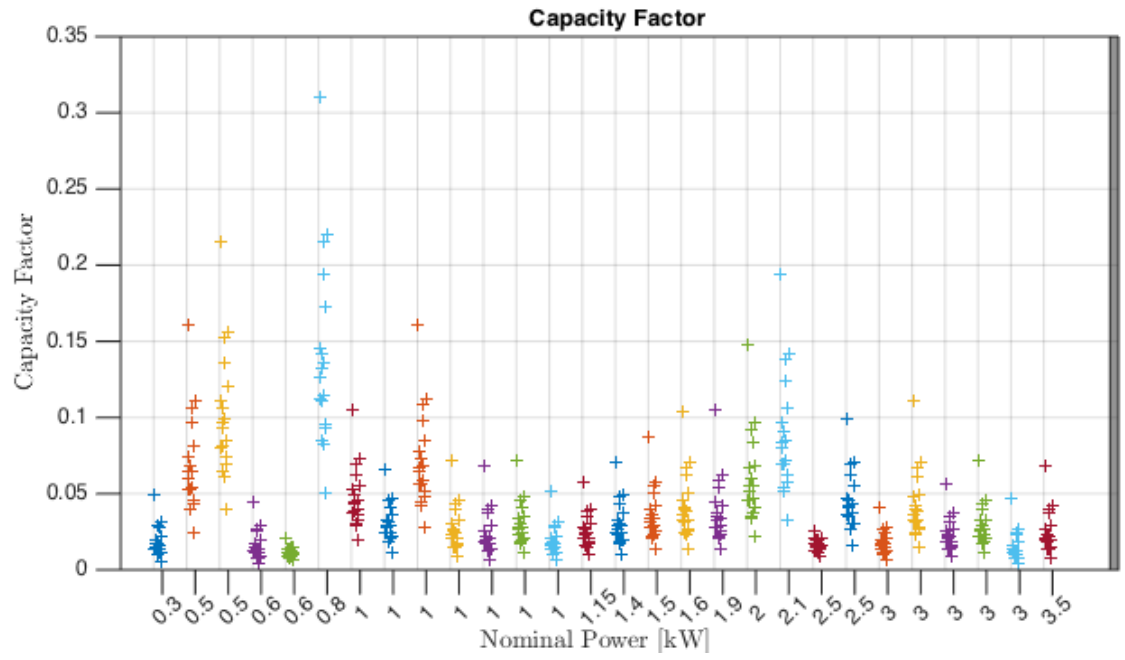

(b)

Figure 13. $C F$ values are calculated for each site and all $28 S W T$ s. It is observed that, for a specific SWT, wind speed conditions are similar within Mexico Valley due to the similar CF values in all locations. Although similar wind conditions exist, power production is defined by the characteristics of the technology represented by the power curve. (a) The capacity factors (CFs) were calculated for each location studied. The nominal power and location axes preserve the same order as that presented in Figure 10a; (b) In order to observe the dependence of $C F$ at particular locations, the corresponding axis was removed.

After observing the individual SWT power performances, wind turbines with equal nominal power values were grouped and plotted. In Figure 14, it is observed that a CF higher than $20 \%$ corresponds to wind turbines with nominal powers of $0.5,0.8$, and $2.1 \mathrm{~kW}$. The first two correspond to technologies with a positive $A N P V$, while the latter corresponds to the negative $A N P V$ that is nearest 
to zero among the turbines evaluated. The manner in which power performance changes with wind conditions is also observed.

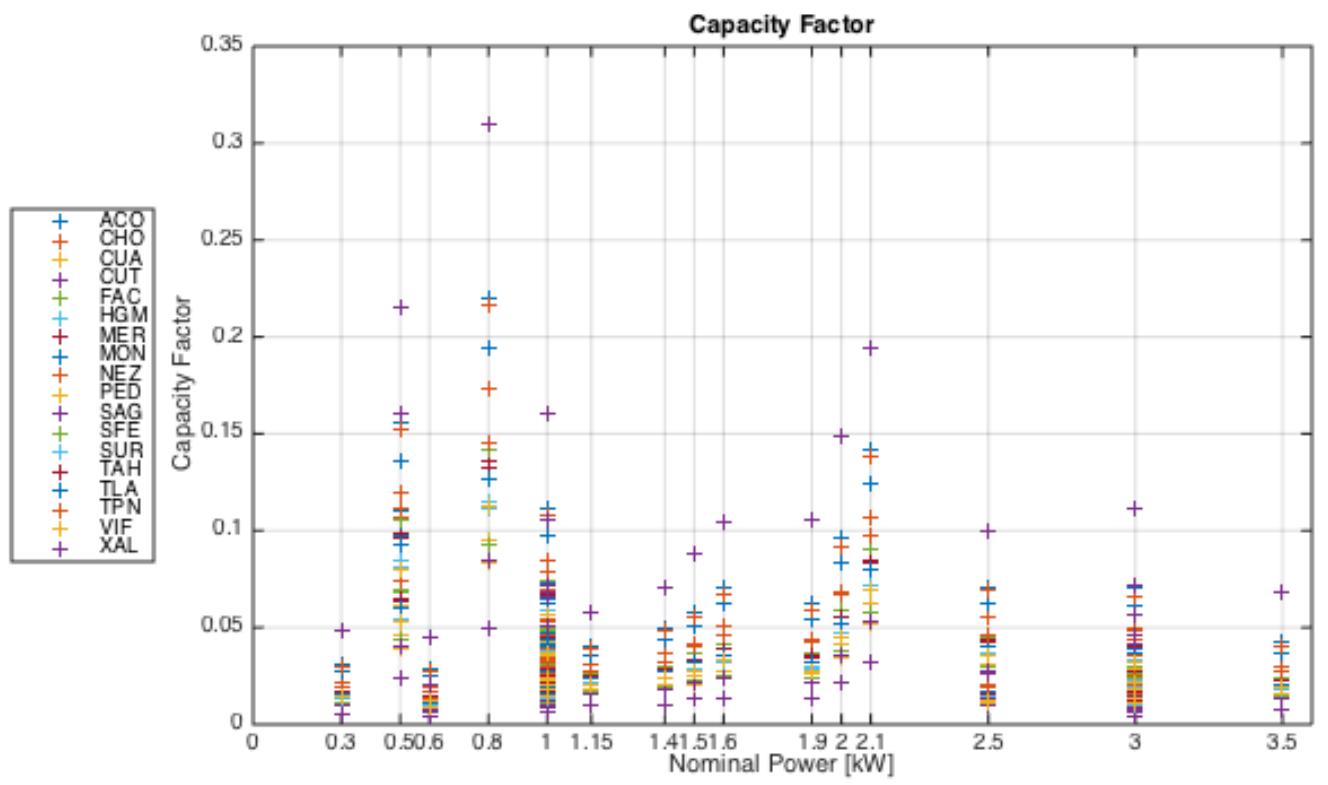

Figure 14. In order to observe general capacity factor tendencies, SWTs with equal nominal powers are grouped and plotted. The turbine with a nominal power of $0.8 \mathrm{~kW}$ presents higher $C F$ values that range from 5 to $35 \%$, and this is also the model with a positive calculated $A N P V$.

From Table 2, it follows that similar wind conditions are present in the VMMA; however, the capacity factor and $A N P V$ change according to the wind parameters and the power curve. In order to establish a relation between $C F$ and $A N P V$, the axis corresponding to the sites is removed. The resulting graph is presented in Figure 15. It preserves the order of nominal power of Figures 11 and 14, and ANPV and $C F$ are plotted and represented by the symbols $\circ$ and + , respectively. The colors are preserved in order to identify locations. It is observed that, in general, $C F$ does not change among locations; however, there are certain locations, namely $A C O$ and $\mathrm{CHO}$, that exhibit the highest values.

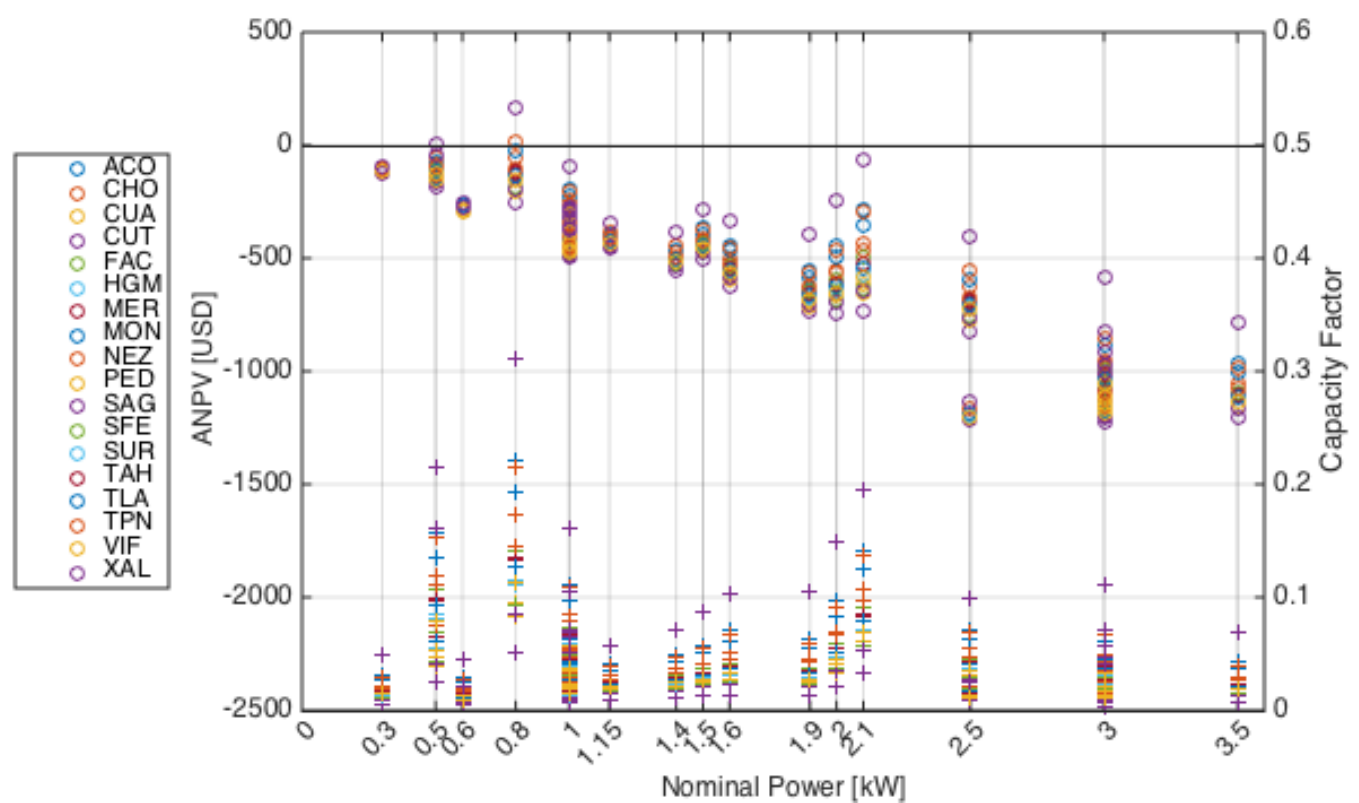

Figure 15. $A N P V$ and $C F$ are represented by the symbols $\circ$ and + , respectively. Similar wind conditions are present within the VMMA. 
The ANPV values calculated exhibit similar behavior among sites, while most of the assessed technologies exhibit negative values. However, the $S W T$ with a nominal power of $0.8 \mathrm{~kW}$ has positive values, and for these scenarios, the calculated CFs are above $20 \%$ - a value that defines the threshold for obtaining a positive $A N P V$. Furthermore, the wind turbine with a nominal power of $2.1 \mathrm{~kW}$ exhibits an $A N P V$ that is equal to zero for one location. Therefore, although wind conditions are similar within the VMMA, SWT performance is a key factor in power production; therefore, reliable methodologies are required for the correct characterization of wind turbine power production.

In order to understand the differences in $A E P$ and $C F$ among the assessed sites, the two locations with the maximum and minimum values of expected wind speeds were selected: $A C O$ and XAL. A common technical characteristic of the selected $S W T$ is the drop in wind speed at $3 \mathrm{~m} / \mathrm{s}$. Figure 16 presents the two Rayleigh distributions of these locations and the probabilities of having wind speeds higher than the cut in wind speed.

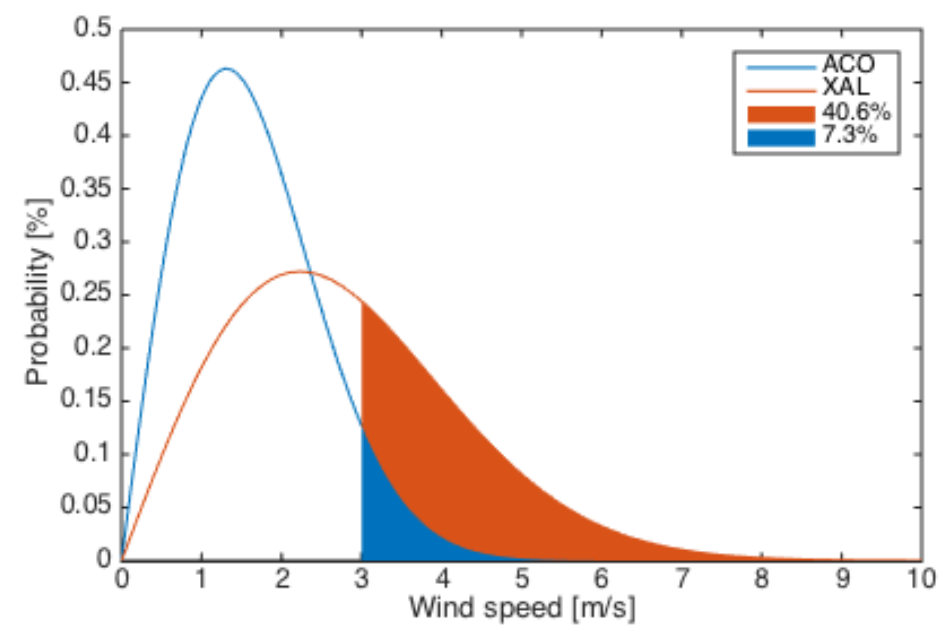

Figure 16. Rayleigh distributions of $A C O$ and $X A L$, which are the locations with minimum and maximum expected wind speeds of the analyzed locations.

As observed in Figure 16 for the ACO and XAL locations, these probabilities are $7.3 \%$ and $40.6 \%$, respectively. Therefore, although the expected wind speeds are very similar, as can be observed in Table 2, the model shape and compatibility with the power curve are factors that determine the $C F$ and, consequently, project reliability.

\section{3. $\mathrm{CO}_{2}$ Mitigation}

An important aspect of power generation through a renewable energy source, such as wind power, is the mitigation of greenhouse gas emissions. These environmental effects are quantifiable and provide additional information regarding project benefits. This information is commonly used by governments to implement economic strategies to promote renewable energy generation.

A common strategy for promoting renewable energy is to associate a substitute price with preventing $\mathrm{CO}_{2}$ emissions [65]. This cost is used as an incentive because it associates economic benefits with each $\mathrm{kWh}$ generated by a renewable energy source.

According to the Secretariat of Environment and Natural Resources (SEMARNAT), the emission factor for electric generation in 2015 was evaluated to be $0.458 \mathrm{TCO} 2 / \mathrm{MWh}$; therefore, it is possible to estimate mitigation from the $A E P$ for each $S W T$.

It is important to mention that, although the methodology presented was developed in an economic context, another method by which to include positive environmental effects is to associate an additional benefit gained from generating electricity through wind turbines: mitigating greenhouse emissions. In order to do so, the annual income per ton of $\mathrm{CO}_{2}$ mitigated is considered. Recent studies have projected that the cost per ton of $\mathrm{CO}_{2}$ in 2020 will be $\$ 43.00$ USD [65]. Thus, Figure 17 presents 
the result of considering this additional income for a group of wind turbines using the closest values to zero. An alternative strategy to improve project feasibility was used in Italy. Regulations allow for subsidizing measures that provide extra benefits in the form of income per kWh generated [13].

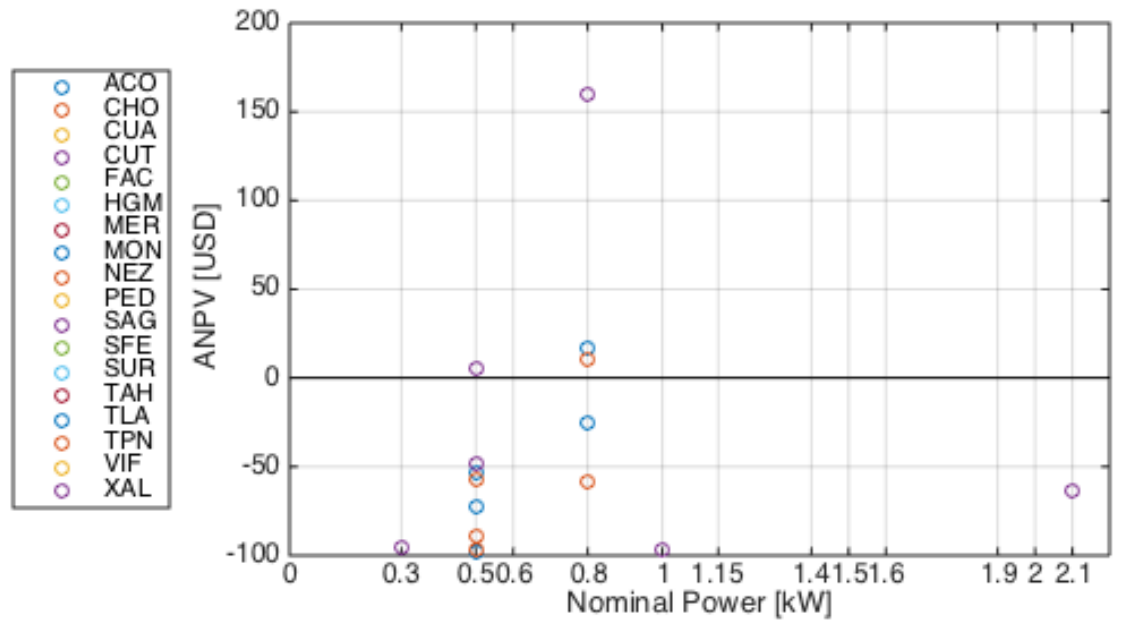

(a)

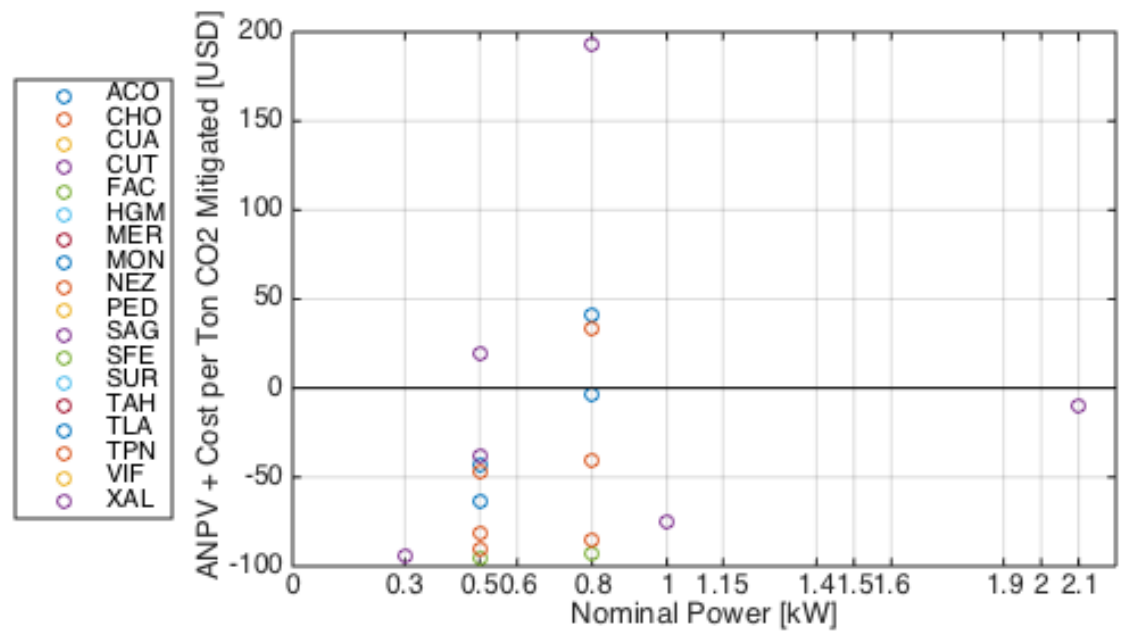

(b)

Figure 17. For each wind turbine, the cost per ton of $\mathrm{CO}_{2}$ mitigated is calculated and added to the corresponding $A N P V$. In order to observe the effects of this addition, the original $A N P V s$ for the $S W T S$ with values that are closest to zero are plotted in (a). In (b), the same set of turbines and locations are plotted for the additional annual income. (a) Group of wind turbines with positive and ANPV values that are closest to zero; (b) Group of wind turbines with ANPV and particular income according to $\mathrm{CO}_{2}$ mitigation.

In Figure 17, it is observed that the general tendency is for the $A N P V$ to increase; however, the number of projects evaluated with positive $A N P V s$ remains: only the two wind turbines (with nominal powers of 0.5 and $0.8 \mathrm{~kW}$ ) exhibit positive values. The wind turbine with a nominal power of $2.1 \mathrm{~kW}$ at the $X A L$ location reduces the total annual loss, but the value remains negative.

\section{Conclusions}

In this work, we calculated the annual energy produced (AEP) for a set of 28 small wind turbines (SWTs) with nominal powers between 0.3 and $3.5 \mathrm{~kW}$ at 18 locations within the Valley of Mexico Metropolitan Area (VMMA). An adjustment to the power production was implemented due to the 
mean time of the time series used in the resource assessment. Furthermore, a techno-economic analysis was developed using the annual net present value (ANPV) technique in order to evaluate project feasibility. To apply this methodology, a scenario with the given the electrical context for a domestic consumer in the VMMA was explored. To show the economic effects while considering annual benefits by means of greenhouse gas mitigation, extra income added to the ANPV is proposed.

The Rayleigh probability density function (PDF) was selected to model all wind speed data sets, and it was observed that expected wind speeds range between 1.65 and $2.79 \mathrm{~m} / \mathrm{s}$, corresponding to the Acolman (ACO) and Xalostoc (XAL) locations, respectively. However, if an SWT's wind speed drops below $3 \mathrm{~m} / \mathrm{s}$, the difference between power production probabilities for both sites is $33.3 \%$.

In the catalog of wind turbines used, certain devices exhibit equal nominal power. After developing the ANPV and capacity factor (CF) studies, results are found to differ among turbines with equal nominal power and similar wind conditions. Therefore, for the SWTs studied, nominal power may not be a standard technical parameter for describing SWT power production.

In order to conduct reliable techno-economic studies, the methodology should include a comparison of technologies with equal or similar nominal powers to make an appropriate technology selection.

Although wind conditions are similar within the VMMA, two technologies exhibit annual incomes. The power performance of an SWT is only represented by its power curve; therefore, it is necessary to develop reliable methodologies to correctly characterize wind turbine power production.

ANPV as the economic methodological basis of assessing reliability allows for the comparison of technologies with different lifetimes. Furthermore, to complement the ANPV results, a $\mathrm{CO}_{2}$ mitigation analysis is presented, thus establishing relationships between $\mathrm{kWh}$ generated by the $\mathrm{SWT}$, tons of $\mathrm{CO}_{2}$ mitigated, and cost per ton of $\mathrm{CO}_{2}$. This methodology allows for the inclusion of an environmental mechanism to promote the penetration of these technologies, and the way in which these benefits may be included in the final results is demonstrated.

Author Contributions: Conceptualization, O.R.-H. and M.M.; methodology, O.R.-H., M.M. and R.C.-A.; software, O.R.-H. and C.L.-V.; validation, C.L.-V. and M.M.; formal analysis, O.R.-H., M.M.; investigation, O.R.-H., H.G., M.M. and C.L.-V.; resources, O.R.-H.; data curation, O.R.-H. and C.L.-V.; writing-original draft preparation, O.R.-H.; writing-review and editing, O.R.-H., M.M. and C.L.-V.; visualization, O.R.-H. and C.L.-V.; supervision, O.R.-H.; project administration, O.R.-H.; funding acquisition, O.R.-H.

Funding: This research was funded by CONACYT-SENER-Sustentabilidad Energética through the project 272063, "Strengthening of the field of Wind Energy in the Doctoral Program in Engineering Field of Knowledge in Energy based in the Institute of Renewable Energies of the National Autonomous University of Mexico"; call, Institutional Strengthening for Energy Sustainability.

Acknowledgments: The authors would like to thank the Secretaría del Medio Ambiente of Mexico City for data availability.

Conflicts of Interest: The authors declare no conflict of interest. The funders had no role in the design of the study; in the collection, analyses, or interpretation of data; in the writing of the manuscript, or in the decision to publish the results.

\section{Nomenclature}

\begin{tabular}{ll}
\multicolumn{1}{c}{ Acronyms } & \\
ACO & Acolman \\
AEP & Annual Energy Produced \\
ANAM & Automatic Network of Atmospheric Monitoring \\
CDF & cumulative distribution function \\
CHO & Chalco \\
CUA & Cuajimalpa \\
CUT & Cuautitlán \\
FAC & FES-Acatlán \\
HGM & Hospital General de México
\end{tabular}




\begin{tabular}{|c|c|}
\hline MER & Merced \\
\hline $\mathrm{MON}$ & Montecillo \\
\hline NEZ & Nezahualcóyotl \\
\hline PDF & probability density function \\
\hline PED & Pedregal \\
\hline SAG & San Agustín \\
\hline SEMARNAT & Secretariat of Environment and Natural Resources \\
\hline SFE & Santa Fe \\
\hline SUR & Santa Úrsula \\
\hline SWT & Small Wind Turbines \\
\hline $\mathrm{TAH}$ & Tláhuac \\
\hline TLA & Tlalnenpantla \\
\hline TPN & Tlalpan \\
\hline VAWT & Vertical Axis Wind Turbine \\
\hline VIF & Villa de las Flores \\
\hline VMMA & Valley of Mexico Metropolitan Area \\
\hline WAsP & Wind Atlas Analysis and Application Program \\
\hline WPTRM & Wind Power Techno-logic Route Map \\
\hline WRF & Weather Research and Forecasting Model \\
\hline XAL & Xalostoc \\
\hline \multicolumn{2}{|c|}{ Greek Symbols } \\
\hline$\alpha$ & shape parameter \\
\hline$\dot{\theta}$ & rotational speed \\
\hline$\lambda$ & constant \\
\hline$\mu$ & expected value \\
\hline$\sigma$ & model dispersion \\
\hline \multicolumn{2}{|c|}{ Roman Symbols } \\
\hline $\bar{x}$ & sample mean \\
\hline $\bar{P}$ & Wnd power mean production \\
\hline $\bar{u}$ & wind speed arithmetic mean \\
\hline$\Delta t$ & period of time recorded \\
\hline$B_{A}$ & benefits \\
\hline$C F$ & Capacity Factor \\
\hline$E_{w}$ & Electric generation \\
\hline$f(u)$ & probability density function \\
\hline$F$ & external force \\
\hline$F_{w}$ & future worth \\
\hline$I$ & angular moment \\
\hline$i$ & discount rate \\
\hline IC & initial cost per $\mathrm{kW}$ installed \\
\hline$m$ & mass \\
\hline$n$ & years of the project \\
\hline$N P V$ & Net Present Value \\
\hline$O \& M_{A}$ & operation and maintenance \\
\hline$P$ & present worth \\
\hline$p_{w}(u)$ & wind turbine power curve \\
\hline$q$ & generalized coordinate system \\
\hline$R$ & radius \\
\hline$S$ & salvage value \\
\hline$T$ & potential energy \\
\hline$U$ & kinetic energy \\
\hline$u$ & wind speed \\
\hline$u_{i}$ & element $\mathrm{i}$ of a wind speed set \\
\hline$x$ & random aleatory variable \\
\hline
\end{tabular}




\section{References}

1. GWEC. GLOBAL WIND REPORT; Technical Report; GWEC: Brussels, Belgium, 2018.

2. GWEC. Global Wind 2016 Report: Annual Market Update; Technical Report; GWEC: Brussels, Belgium, 2017.

3. Wiser, R.; Bolinger, M. 2016 Wind Technologies Market Report; Technical Report; U.S. Department of Energy: Washington, DC, USA, 2016.

4. Tummala, A.; Velamati, R.K.; Sinha, D.K.; Indraja, V.; Krishna, V.H. A review on small scale wind turbines. Renew. Sustain. Energy Rev. 2016, 56, 1351-1371. [CrossRef]

5. Pitteloud, J.D.; Gsanger, S. Small Wind World Report 2016; Technical Report; World Wind Energy Association: Bonn, Germany, 2015.

6. Kammen, D.M.; Sunter, D.A. City-integrated renewable energy for urban sustainability. Science 2016, 352, 922-928. [CrossRef] [PubMed]

7. Orrel, A.; Foster, N. 2015 Distributed Wind Market Report I Department of Energy; Technical Report; Pacific Northwest National Laboratory prepared for the Department of Energy: Richland, WC, USA, 2016.

8. Liu, S.Y.; Ho, Y.F. Wind energy applications for Taiwan buildings: What are the challenges and strategies for small wind energy systems exploitation? Renew. Sustain. Energy Rev. 2016. [CrossRef]

9. Murthy, K.S.R.; Rahi, O.P. A comprehensive review of wind resource assessment. Renew. Sustain. Energy Rev. 2017, 72, 1320-1342. [CrossRef]

10. Micallef, D.; van Bussel, G. A Review of Urban Wind Energy Research: Aerodynamics and Other Challenges. Energies 2018, 11, 2204. [CrossRef]

11. Drew, D.R.; Barlow, J.F.; Cockerill, T.T. Estimating the potential yield of small wind turbines in urban areas: A case study for Greater London, UK. J. Wind Eng. Ind. Aerodyn. 2013, 115, 104-111. [CrossRef]

12. McIntyre, J.H.; Lubitz, W.D.; Stiver, W.H. Local wind-energy potential for the city of Guelph, Ontario (Canada). Renew. Energy 2011. [CrossRef]

13. Messineo, A.; Culotta, S. Evaluating the performances of small wind turbines: A case study in the South of Italy. Energy Procedia 2012, 16, 137-145. [CrossRef]

14. Irshad, W.; Goh, K.; Kubie, J. Wind resource assessment in the Edinburgh region. In Proceedings of the WNWEC 2009-2009 World Non-Grid-Connected Wind Power Energy Conference, Nanjing, China, 24-26 September 2009.

15. Elnaggar, M.; Edwan, E.; Ritter, M. Wind Energy Potential of Gaza Using Small Wind Turbines: A Feasibility Study. Energies 2017, 10, 1229. [CrossRef]

16. Li, Q.S.; Shu, Z.R.; Chen, F.B. Performance assessment of tall building-integrated wind turbines for power generation. Appl. Energy 2016. [CrossRef]

17. Hakimi, R.; Lubitz, W.D. Wind environment at a roof-mounted wind turbine on a peaked roof building. Int. J. Sustain. Energy 2016, 35, 172-189. [CrossRef]

18. Drew, D.R.; Barlow, J.F.; Cockerill, T.T.; Vahdati, M.M. The importance of accurate wind resource assessment for evaluating the economic viability of small wind turbines. Renew. Energy 2015, 77, 493-500. [CrossRef]

19. Emejeamara, F.C.; Tomlin, A.S.; Millward-Hopkins, J.T. Urban wind: Characterisation of useful gust and energy capture. Renew. Energy 2015, 81, 162-172. [CrossRef]

20. Emejeamara, F.C.; Tomlin, A.S. A method for mapping the turbulence intensity and excess energy available to building mounted wind turbines over a UK City. Wind Energy 2016, 19, 1423-1438. [CrossRef]

21. Rodríguez-Hernández, O.; del Río, J.A.; Jaramillo, O.A. The importance of mean time in power resource assessment for small wind turbine applications. Energy Sustain. Dev. 2016, 30, 32-38. [CrossRef]

22. Acosta, J.L.; Combe, K.; Djokić, S.Ž.; Hernando-Gil, I. Performance assessment of micro and small-scale wind turbines in urban areas. IEEE Syst. J. 2012, 6, 152-163. [CrossRef]

23. Hulio, Z.H.; Jiang, W. Site-specific technical and economic analysis of wind power potential and energy generation using Weibull parameters. World J. Sci. Technol. Sustain. Dev. 2018, 15, 35-53. [CrossRef]

24. Chadee, X.T.; Clarke, R.M. Wind resources and the levelized cost of wind generated electricity in the Caribbean islands of Trinidad and Tobago. Renew. Sustain. Energy Rev. 2018, 81, 2526-2540. [CrossRef]

25. Minaeian, A.; Sedaghat, A.; Mostafaeipour, A.; Akbar Alemrajabi, A. Exploring economy of small communities and households by investing on harnessing wind energy in the province of Sistan-Baluchestan in Iran. Renew. Sustain. Energy Rev. 2017, 74, 835-847. [CrossRef] 
26. Cooney, C.; Byrne, R.; Lyons, W.; O’Rourke, F. Performance characterisation of a commercial-scale wind turbine operating in an urban environment, using real data. Energy Sustain. Dev. 2017, 36, 44-54. [CrossRef]

27. Sunderland, K.M.; Narayana, M.; Putrus, G.; Conlon, M.F.; McDonald, S. The cost of energy associated with micro wind generation: International case studies of rural and urban installations. Energy 2016, 109, 818-829. [CrossRef]

28. Alemán-Nava, G.S.; Casiano-Flores, V.H.; Cárdenas-Chávez, D.L.; Díaz-Chavez, R.; Scarlat, N.; Mahlknecht, J.; Dallemand, J.F.; Parra, R. Renewable energy research progress in Mexico: A review. Renew. Sustain. Energy Rev. 2014, 32, 140-153. [CrossRef]

29. Elliott, D.; Schwartz, M.; Scott, G.; Haymes, S. Wind Energy Resource Atlas of Oaxaca; Technical Report; NREL: Golden, CO, USA, 2004.

30. Ríos Patrón, E.; Ramos Palmeros, R.; Cruz Marqués, R.; de la Fuente Melo, C.A.; Ortíz Gallardo, V.G.; González Ortíz, A.; Ortíz Gallardo, M.G. Mapa de ruta Tecnológica Energía Eólica en Tierra; Technical Report; Secretaría de Energía: Ciudad de México, Mexico, 2017.

31. Hernandez-Escobedo, Q. Wind Energy Assessment for Small Urban Communities in the Baja California Peninsula, Mexico. Energies 2016, 9, 805. [CrossRef]

32. Jaramillo, O.A.; Saldana, R.; Miranda, U. Wind power potential of Baja California Sur, México. Renew. Energy 2004, 29, 2087-2100. [CrossRef]

33. Cancino-Solórzano, Y.; Gutiérrez-Trashorras, A.J.; Xiberta-Bernat, J. Analytical methods for wind persistence: Their application in assessing the best site for a wind farm in the State of Veracruz, Mexico. Renew. Energy 2010, 35, 2844-2852. [CrossRef]

34. Cancino-Solórzano, Y.; Xiberta-Bernat, J. Statistical analysis of wind power in the region of Veracruz (Mexico). Renew. Energy 2009, 34, 1628-1634. [CrossRef]

35. Carrasco-Díaz, M.; Rivas, D.; Orozco-Contreras, M.; Sánchez-Montante, O. An assessment of wind power potential along the coast of Tamaulipas, northeastern Mexico. Renew. Energy 2015, 78, 295-305. [CrossRef]

36. Hernández-Escobedo, Q.; Saldaña-Flores, R.; Rodríguez-García, E.R.; Manzano-Agugliaro, F. Wind energy resource in Northern Mexico. Renew. Sustain. Energy Rev. 2014, 32, 890-914. [CrossRef]

37. Figueroa-Espinoza, B.; Salles, P.; Zavala-Hidalgo, J. On the wind power potential in the northwest of the Yucatan Peninsula in Mexico. Atmósfera 2014, 27, 77-89. [CrossRef]

38. Beltran, L.; Villanueva Arcos, E.; Muñozcano, L.; Rodriguez, J.; Ramirez, M.; Gasca, S.; Ramírez, A.; Rocha, D.; Avila, D.; Navarrete, E.; et al. Reporte de Avance de Energías Limpias; Technical Report; Secretaría de Energía: Ciudad de México, Mexico, 2017.

39. Alexandri, R.; Muñoz, L.; Guerrero, L.; Rodríguez, F.; Ubaldo, A.; Ramos, A. Prospectiva de Energías Renovables 2016-2030; Technical Report; Secretaría de Energía: México, Mexico, 2016.

40. Rodriguez-Hernandez, O.; del Río, J.A.; Jaramillo, O.A.; Martínez, M. Wind Power Error Estimation in Resource Assessments. PLoS ONE 2015, 10, e0124830. [CrossRef]

41. Georgeson, L.; Maslin, M.; Poessinouw, M.; Howard, S. Adaptation responses to climate change differ between global megacities. Nat. Clim. Chang. 2016, 6, 584-588. [CrossRef]

42. Martos, A.; Pacheco-Torres, R.; Ordóñez, J.; Jadraque-Gago, E. Towards successful environmental performance of sustainable cities: Intervening sectors. A review. Renew. Sustain. Energy Rev. 2016, 57, 479-495. [CrossRef]

43. Shokrzadeh, S.; Bibeau, E. Sustainable integration of intermittent renewable energy and electrified light-duty transportation through repurposing batteries of plug-in electric vehicles. Energy 2016, 106, 701-711. [CrossRef]

44. Karan, E.; Mohammadpour, A.; Asadi, S. Integrating building and transportation energy use to design a comprehensive greenhouse gas mitigation strategy. Appl. Energy 2016, 165, 234-243. [CrossRef]

45. SENER. Sistema de Información Energética. 2016. Available online: http://sie.energia.gob.mx/bdiController. do?action=temas (accessed on 2 February 2018).

46. Calderón-Garcidueñas, L.; Kulesza, R.J.; Doty, R.L.; D'Angiulli, A.; Torres-Jardón, R. Megacities air pollution problems: Mexico City Metropolitan Area critical issues on the central nervous system pediatric impact. Environ. Res. 2015, 137, 157-169. [CrossRef] [PubMed]

47. ANAM. Automatic Network of Atmospheric Monitoring 2018. Available online: http://www.aire.cdmx. gob.mx/default.php (accessed on 10 February 2018)., 2016.

48. De Foy, B.; Clappier, A.; Molina, L.T.; Molina, M.J. Distinct wind convergence patterns in the Mexico City basin due to the interaction of the gap winds with the synoptic flow. Atmos. Chem. Phys. 2006, 6, 1249-1265. [CrossRef] 
49. Carreón-Sierra, S.; Salcido, A.; Castro, T.; Celada-Murillo, A.T. Cluster analysis of the wind events and seasonal wind circulation patterns in the Mexico City region. Atmosphere 2015, 6, 1006-1031. [CrossRef]

50. de Foy, B.; Caetano, E.; Magaña, V.; Zitácuaro, A.; Cárdenas, B.; Retama, A.; Ramos, R.; Molina, L.; Molina, M. Mexico City basin wind circulation during the MCMA-2003 field campaign. Atmos. Chem. Phys. 2005, 5, 2267-2288. [CrossRef]

51. Carta, J.A.; Ramírez, P.; Velázquez, S. A review of wind speed probability distributions used in wind energy analysis. Case studies in the Canary Islands. Renew. Sustain. Energy Rev. 2009, 13, 933-955. [CrossRef]

52. Kanyako, F.; Janajreh, I. Implementation and economical study of HAWT under different wind scenarios. Sustain. Cities Soc. 2015, 15, 153-160. [CrossRef]

53. Khahro, S.F.; Tabbassum, K.; Mohammad Soomro, A.; Liao, X.; Alvi, M.B.; Dong, L.; Manzoor, M.F. Techno-economical evaluation of wind energy potential and analysis of power generation from wind at Gharo, Sindh Pakistan. Renew. Sustain. Energy Rev. 2014, 35, 460-474. [CrossRef]

54. Tiang, T.L.; Ishak, D. Technical review of wind energy potential as small-scale power generation sources in Penang Island Malaysia. Renew. Sustain. Energy Rev. 2012, 16, 3034-3042. [CrossRef]

55. Manwell, J.F.; McGowan, J.G.; Rogers, A.L. Wind Energy Explained: Theory, Design and Application; John Wiley \& Sons: Hoboken, NJ, USA, 2010.

56. Weekes, S.M.; Tomlin, A.S. Evaluation of a semi-empirical model for predicting the wind energy resource relevant to small-scale wind turbines. Renew. Energy 2013, 50, 280-288. [CrossRef]

57. Ajayi, O.O.; Fagbenle, R.O.; Katende, J.; Ndambuki, J.M.; Omole, D.O.; Badejo, A.A. Wind Energy Study and Energy Cost of Wind Electricity Generation in Nigeria: Past and Recent Results and a Case Study for South West Nigeria. Energies 2014, 7, 8508-8534. [CrossRef]

58. Johnson, N.H.; Solomon, B.D. A Net-Present Value Analysis for a Wind Turbine Purchase at a Small US College. Energies 2010, 3, 943-959. [CrossRef]

59. Remer, D.S.; Nieto, A.P. A compendium and comparison of 25 project evaluation techniques. Part 1: Net present value and rate of return methods. Int. J. Prod. Econ. 1995, 42, 79-96. [CrossRef]

60. CFE. Tarifas Domésticas de Alto Consumo 2017. Available online: http://app.cfe.gob.mx/Aplicaciones/ CCFE/Tarifas/Tarifas (accessed on 6 November 2017).

61. INEGI. Anuario Estadístico y Geográfico del Distrito Federal 2015; Technical Report; Instituto Nacional de Estadística y Geografía: Mexico, Mexico, 2015.

62. INEGI. Anuario Estadístio y Geográfico de México 2015; Technical Report; Instituto Nacional de Estadística y Geografía: Mexico, Mexico, 2015.

63. Grieser, B.; Sunak, Y.; Madlener, R. Economics of small wind turbines in urban settings: An empirical investigation for Germany. Renew. Energy 2015, 78, 334-350. [CrossRef]

64. Sathyajith, M. Wind Energy: Fundamentals, Resource Analysis and Economics; Springer: Berlin/Heidelberg, Germany, 2006.

65. Bakhtyar, B.; Fudholi, A.; Hassan, K.; Azam, M.; Lim, C.H.; Chan, N.W.; Sopian, K. Review of $\mathrm{CO}_{2}$ price in Europe using feed-in tariff rates. Renew. Sustain. Energy Rev. 2017, 69, 685-691. [CrossRef]

(c) 2019 by the authors. Licensee MDPI, Basel, Switzerland. This article is an open access article distributed under the terms and conditions of the Creative Commons Attribution (CC BY) license (http:/ / creativecommons.org/licenses/by/4.0/). 